\title{
A FLÓRULA RUPESTRE DO PICO DE ITABIRITO, MINAS GERAIS, BRASIL: LISTA DAS PLANTAS VASCULARES
}

\author{
WAGNER ANTUNES TEIXEIRA* \& JOSÉ PIRES DE LEMOS FILHO**
}

\author{
* Secretaria de Estado de Meio Ambiente e Desenvolvimento Sustentável - SEMAD, Prédio Minas 1ํe 2ํㅜ \\ andar, Cidade Administrativa do Estado de Minas Gerais, Rodovia Prefeito Américo Gianetti s.n., Bairro Serra \\ Verde, 31630-900 - Belo Horizonte, Minas Gerais, Brasil. e-mail: mawapedro@yahoo.com.br \\ ** Departamento de Botânica, ICB, Universidade Federal de Minas Gerais, Av. Antônio Carlos, 6627, \\ Pampulha, 31270-901 - Belo Horizonte, MG, Brasil.
}

\begin{abstract}
The rupestrian florula do Pico de Itabirito, Minas Gerais, Brazil: a list of vascular plants). This article presents a new survey of species of vascular plants from the campos rupestres of the Espinhaço Range in eastern Brazil. The study area is included in the Quadrilátero Ferrífero in Minas Gerais state, in the region of the Pico de Itabirito, municipality of Itabirito, around $20^{\circ} 13^{\prime} 43^{\prime \prime} \mathrm{S}$ and $43^{\circ} 51^{\prime} 39 \mathrm{~W}$. The surveyed area is around 1193 ha, with altitude reaching more than $1300 \mathrm{~m}$ above sea level, with a vegetation mostly formed by rupestrian fields, either on iron and quartizitic substrates (denominated campo rupestre ferrífero and campo rupestre quartzítico, respectively). 722 species were found, distributed in 100 families and 384 genera. The ten richest families are Asteraceae (99 spp.), Orchidaceae (62 spp.), Melastomataceae (50 spp.), Leguminosae (36 spp.), Poaceae (30 spp.), Rubiaceae (26 spp.), Apocynaceae (23 spp.), Myrtaceae (22 spp.), Malpighiaceae (18 spp.), Cyperaceae (15 spp.), Eriocaulaceae (14 spp.) and Solanaceae (13 spp.). 47 species are included in the 2012 revised version of the List of Endangered Species of the State of Minas Gerais.
\end{abstract}

Key words: campo rupestre, campo ferruginoso, Espinhaço Range, phytogeography.

Resumo - (A flórula rupestre do Pico de Itabirito, Minas Gerais, Brasil: lista das plantas vasculares). O presente trabalho apresenta um novo inventário de espécies de plantas vasculares de campos rupestres da Cadeia do Espinhaço. A área de estudos insere-se no Quadrilátero Ferrífero de Minas Gerais, na região do Pico de Itabirito, município de Itabirito, cujas coordenadas geográficas centrais são $20^{\circ} 13^{\prime} 43^{\prime \prime} \mathrm{S}$ e $43^{\circ} 51^{\prime} 39^{\prime \prime} \mathrm{W}$. A área amostrada possui 1193 ha, com cotas superiores a 1300 m acima do nível do mar, cuja vegetação é constituída predominantemente por campos rupestres ferríferos e quartzíticos. Foram encontradas 722 espécies distribuídas em 100 famílias e 384 gêneros. As dez famílias com maior riqueza específica são Asteraceae (99 spp.), Orchidaceae (62 spp.), Melastomataceae (50 spp.), Leguminosae (36 spp.), Poaceae (30 spp.), Rubiaceae (26 spp.), Apocynaceae (23 spp.), Myrtaceae (22 spp.), Malpighiaceae (18 spp.), Cyperaceae (15 spp.), Eriocaulaceae (14 spp.) e Solanaceae (13 spp.). 47 espécies constam da revisão de 2012 das Listas das Espécies da Flora Ameaçadas de Extinção do Estado de Minas Gerais.

Palavra-chave: campo ferruginoso, campo rupestre, Cadeia do Espinhaço, fitogeografia.

\section{Introdução}

A Serra do Espinhaço, termo introduzido por Eschwege (1822), também conhecida como Serra Geral (King 1956) ou Cadeia do Espinhaço (e.g. Giulietti et al. 1997), representa a faixa orogênica mais extensa e contínua do território brasileiro (AlmeidaAbreu \& Renger 2002). Originada no final do Precambriano, constitui um conjunto orográfico com predominância de altitudes entre 800 e 1800 m (Magalhães 1954), que se alonga por cerca de 1200 km na direção N-S, desde a região de Belo Horizonte até os limites norte da Bahia com os estados de Pernambuco e Piauí (Almeida-Abreu \& Renger 2002). Sua largura varia entre 50 e $100 \mathrm{~km}$ (Giulietti et al. 1987, Harley 1995). Essa região do Escudo Cristalino Brasileiro constitui o divisor de águas entre os tributários do São Francisco e aqueles que se dirigem para o Atlântico (Derby 1906, Moreira 1977, Renger 1979, Abreu 1984). No Espinhaço pode ser distinguido um setor mineiro, cujo limite norte encontra-se nas elevações isoladas das proximidades de Monte Azul e Montezuma, separado do setor baiano, denominado de Chapada Diamantina (Fig. 1). Entre estes é perceptível um hiato de terrenos baixos, onde as elevações acima de $1000 \mathrm{~m}$ ficam reduzidas e bem afastadas entre si (Harley 1988, Pirani et al. 2003).

As rochas, sobretudo quartzitos e arenitos, que compõem a maioria dos afloramentos rochosos do Espinhaço são muito antigas, com idades em torno de 500-600 Ma (Uhlein 1991, Almeida-Abreu 1993). Essas rochas fazem parte do Super-grupo São Francisco (Fernandes et. al. 1982), apresentando-se mais resistentes aos processos erosivos, o que resultou na estruturação das serras que conformam esta cordilheira continental. Os solos provenientes da decomposição de quartzitos e arenitos são caracteristicamente pedregosos, arenosos, rasos, e apresentam baixa capacidade de retenção de água (Ferreira \& Magalhães 1977, Vitta 1995, Giulietti et al. 


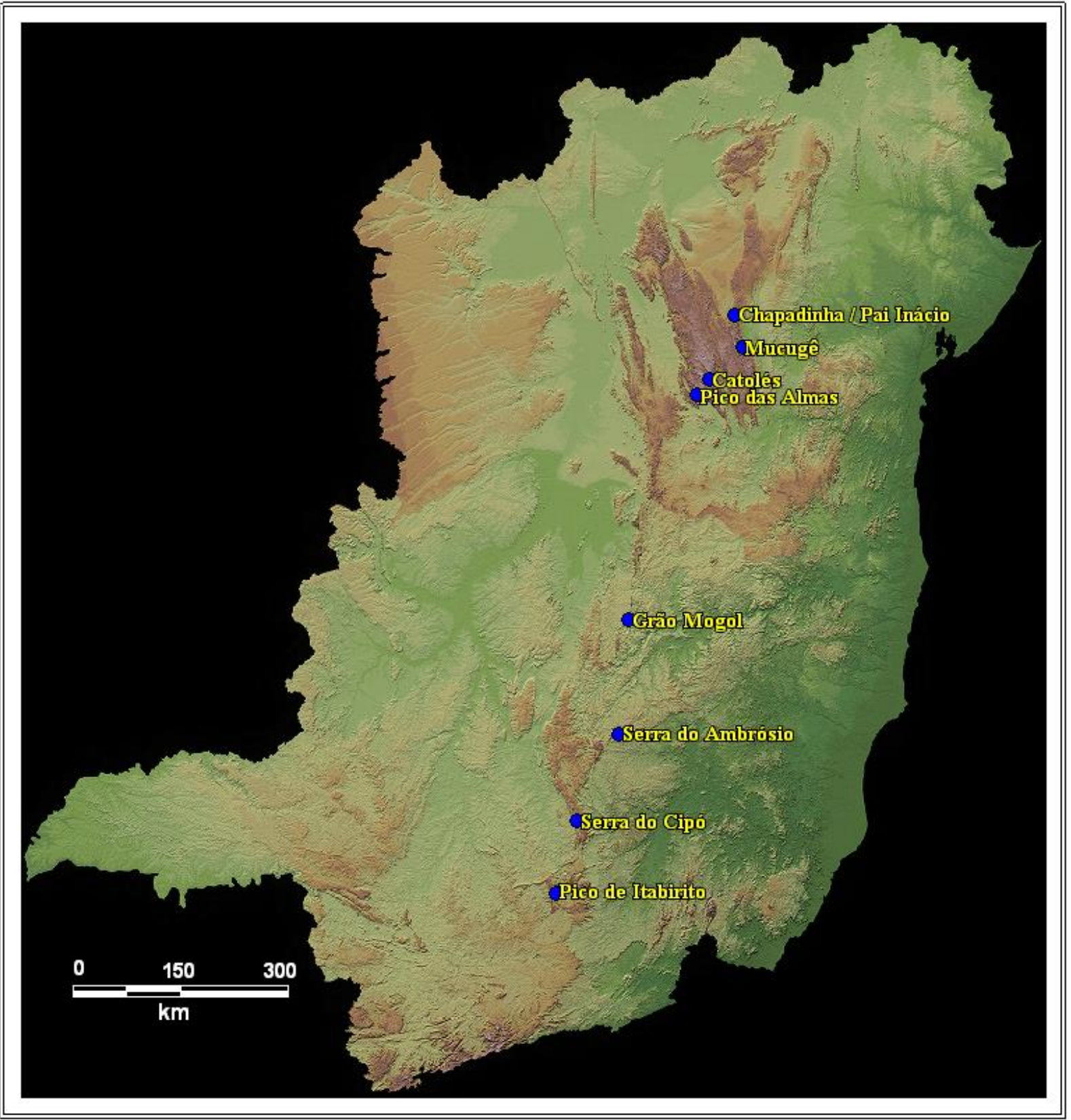

Fig. 1 - Relevo dos estados da Bahia e Minas Gerais, destacando na parte central a Cadeia do Espinhaço, onde estão assinalados alguns locais com levantamentos florísticos já publicados; o Pico do Itabirito é a mais meridional de todas as áreas estudadas. 
A flórula rupestre do Pico de Itabirito, Minas Gerais, Brasil

1997). Apresentam-se também, geralmente, pobres em nutrientes e matéria orgânica (Pirani et al. 2003, Benites et al. 2007). Onde a drenagem é deficiente, podem ocorrer brejos oligotróficos, em que, por vezes, desenvolvem-se turfeiras (Giulietti et al. 2000), denominadas campos brejosos por Vitta (1995).

O clima da Serra do Espinhaço tem sido enquadrado no tipo Cwb de Köppen (1936), tropical de altitude, caracterizado por apresentar invernos secos e verões brandos e chuvosos, com temperaturas médias inferiores a 22ํㅡ (Harley 1995, Lima \& Pirani 2003). Enquanto a precipitação média anual na Cadeia do Espinhaço em Minas Gerais está por volta de 1500 $\mathrm{mm}$, segundo Harley (1995) e, a $1600 \mathrm{~mm}$, segundo Lima \& Pirani (2003), os valores encontrados na Chapada Diamantina (Bahia) são menores, devido ao clima semiárido das terras baixas adjacentes (Harley 1995). Ao longo da Cadeia do Espinhaço há grande diversidade climática, em razão de fatores variáveis, a exemplo da sua heterogeneidade fisiográfica, compartimentação altimétrica, extensão territorial, principalmente em relação à latitude, e dinamismo das massas de ar (Valadão 1998). Esse último fator é fundamental, uma vez que está intimamente associado ao comportamento da temperatura e à distribuição pluviométrica (Valadão 1998).

Ab'Saber (1990) considera a Cadeia do Espinhaço em Minas Gerais, como um divisor entre o domínio morfoclimático dos cerrados e o tropical atlântico. A parte baiana dessa formação interpõe-se entre as caatingas e o complexo vegetacional dos planaltos e baixos rios do sul da Bahia. Entre as formações vegetacionais que recobrem a Serra do Espinhaço, destacam-se os campos rupestres, assim denominados pela primeira vez por Magalhães (1966), referindo-se às formações sobre substrato quartzítico. Tal denominação tem prevalecido entre os autores posteriores estudando a biota dessa região (e.g. Giulietti et al. 1987, 1997). Os campos rupestres geralmente ocorrem em cotas superiores a $900 \mathrm{~m}$, associados aos afloramentos rochosos e solos litólicos e arenosos adjacentes. Essa vegetação é tão peculiar que foi distinta por Prance (1994a, b) como fitocória dos campos rupestres, na sua proposição de uma nova classificação das províncias fitogeográficas (fitocórias) da América do Sul neotropical. Este autor também destacou que essa fitocória constitui um centro de endemismo do tipo arquipélago, devido ao fato de as espécies terem distribuições descontínuas, ocorrendo em topos de montanhas isoladas entre si. Joly (1970) e Giulietti \& Pirani (1988) apontam que, além da alta riqueza florística, os campos rupestres constituem a formação vegetacional brasileira com maior número de espécies endêmicas.

Nos campos rupestres observa-se uma grande diversidade de habitats, condicionados pela topografia, tipo de solo, natureza e proporção das rochas expostas, capacidade de retenção de água, condições microclimáticas, que se expressam na diversificada fitofisionomia (Conceição \& Giulietti 2002, Conceição \& Pirani 2005, Alves \& Kolbek 2009). Interessantes especializações morfofisiológicas são observadas nos componentes da flora local, em clara adaptação às condições ambientais (Joly 1970, Giulietti et al. 1987, 1997, 2000). A aparente uniformidade geral da fisionomia dos campos rupestres é dada pela manutenção das mesmas famílias botânicas e, especialmente, pela convergência de hábitos em famílias distantes filogeneticamente, expressando variadas estratégias de sobrevivência em adaptação ao ambiente onde ocorrem (Menezes \& Giulietti 1986, Giulietti et al. 1987, 1997). Ururahy et al. (1984) e Rodela (1998), comparando essa formação aos cerrados, mencionam que os campos rupestres correspondem a fisionomias montanhosas raras de vegetação, onde são encontrados endemismos específicos que refletem condições ecológicas diferentes daquelas da vegetação regional ao seu redor, provável indicação de serem resultado de isolamento antigo.

Dede o século XIX a vegetação das serras do Espinhaço tem atraído a atenção de naturalistas, como Spix \& Martius (1828), Saint-Hilaire (1833), Pohl (1837), Gardner (1846). Posteriormente, outros pesquisadores que realizaram coletas e pesquisas botânicas nestas serras incluem Christ (1900), Silveira (1908, 1928, 1931), Hoehne (1927), Barreto (1935, 1949), Magalhães (1953, 1954, 1956, 1966), Lisboa (1971) e Ferreira \& Magalhães (1977). Mais recentemente, principalmente nas últimas três décadas, intensificaram-se as pesquisas botânicas em florística, taxonomia, fitossociologia, anatomia, fisiologia e fitoquímica feitas nessa vegetação, sobretudo de equipes da Universidade de São Paulo, Universidade Estadual de Campinas, Instituto de Botânica de São Paulo, Universidade Federal de Minas Gerais, Universidade Estadual de Feira de Santana, Universidade Federal da Bahia, Museu Nacional do Rio de Janeiro e Royal Botanic Gardens de Kew, Inglaterra e como resultado diversos setores do Espinhaço contam com floras ou listas florísticas completas publicadas (Pirani et al. 2003, Alves \& Kolbek 2009). Lohmann \& Pirani (1996) sintetizaram os aspectos fundamentais que têm motivado os estudos botânicos e biogeográficos nesse conjunto orográfico em: 1- o fato de o Espinhaço constituir o centro de diversidade de numerosos gêneros de muitas famílias, sendo algumas incomuns ou mesmo ausentes em outras formações brasileiras; 2- a sua flora campestre, em especial, ser muito rica, com elevado grau de endemismos; 3- apresentar uma diversidade paisagística, condicionada basicamente à topografia acidentada dos terrenos; 4- os interessantes padrões de distribuição geográfica das espécies, com vários tipos de disjunções, decorrentes do caráter "insular" das serras que compõem a cadeia, ilhadas parcialmente dentro do domínio morfoclimático dos Cerrados (aspecto verificado na maior parte do setor mineiro do Espinhaço) e parcialmente dentro do domínio das Caatingas (no setor da Bahia e na porção setentrional do setor de Minas Gerais desta cadeia), conforme evidenciado por Giulietti \& Pirani (1988), Harley (1988) e Giulietti et al. (1997). 
Floras locais têm sido utilizadas para provar teorias biogeográficas (Hadley 1987), para identificar zonas ou áreas florísticas (Taylor 1977, McLaughlin 1986, 1989), para examinar padrões de diversidade das espécies (Bowers \& MacLaughlin 1982, Hadley 1987, Rosenweig 1995, Mittermeier et al. 1999), para identificar vias de migração e barreiras (Harper et al. 1978, Hadley 1987) e para provar modelos de abundância de espécies por gênero (Simpson \& Todzia 1990).

Além da necessidade incontestável de incrementar o conhecimento sobre a composição florística de muitos biomas brasileiros, sobretudo com vistas à sua adequada exploração e conservação, todos os empregos de dados florísticos supramencionados justificam o esforço de compilação de novos inventários em áreas serranas do Espinhaço ainda pouco conhecidas, como 0 realizado no presente trabalho. Este trata do levantamento florístico das áreas campestres e ecotonais da região do Pico do Itabirito, Minas Gerais. Essa região já foi objeto de levantamento florístico por Brandão et al. (1989 e 1991), focando as áreas campestres e zonas de contato, no qual foram identificadas 412 espécies de plantas vasculares. A partir de 1993 também foram desenvolvidas na região pesquisas relacionadas à sucessão vegetacional em uma cava de mineração (Teixeira 1997), resultando em artigo específico sobre metais pesados em folhas de espécies lenhosas colonizadoras de mina de ferro (Teixeira \& LemosFilho 1998) e outro sobre fatores que interferem na colonização de espécies lenhosas em cava de mineração ferrífera (Teixeira \& Lemos-Filho 2002).

O avanço da mineração para extração de pedras ornamentais e os empreendimentos imobiliários e turísticos estão crescendo vertiginosamente sobre os ambientes serranos em várias partes do Espinhaço. Os campos rupestres desenvolvidos sobre áreas ferríferas encontram-se em situação acentuadamente mais grave (e.g. Jacobi \& Carmo 2012). Ao se observar as solicitações para pesquisa e lavra de minérios do Quadrilátero Ferrífero de Minas Gerais no Departamento Nacional de Produção Mineral - DNPM (vide Sistema de Informações Geográficas da Mineração, www.dnpm.gov.br), verifica-se que todas as áreas onde ocorre esta formação estão requeridas, inclusive aquelas inseridas em unidades de conservação. A crescente demanda mundial por materiais metálicos tem provocado intensa exploração de minério de ferro nesta região, com a adição ou expansão de novas minas. Deve-se considerar também, o fato de que o Quadrilátero Ferrífero constitui a região mais populosa do estado, onde estão sendo implantados vários projetos imobiliários (condomínios residenciais), principalmente na região sul de Belo Horizonte, Minas Gerais.

Desse modo, os campos rupestres do Espinhaço, com sua ocorrência bastante fragmentada, com várias disjunções, e abrigando uma alta diversidade de espécies restritas a habitats específicos, necessitam de mais explorações biológicas a campo e de novos estudos taxonômicos, florísticos e ecológicos, que forneçam subsídios importantes para indicar a forma de condução e distribuição de unidades de conservação sobre esta cordilheira.

O presente inventário florístico visa contribuir para o melhor conhecimento da vegetação serrana do Espinhaço meridional e prover subsídios para sua conservação.

\section{Material e métodos}

\section{Caracterização da área de estudo}

A região do Pico de Itabirito insere-se nos limites do Quadrilátero Ferrífero de Minas Gerais (Fig. 2), porção meridional do Cráton do São Francisco, núcleo cratônico estabilizado no Proterozóico Inferior (CERN 2006). O Quadrilátero Ferrífero é uma área com aproximadamente $7000 \mathrm{~km}^{2}$, centrada nas coordenadas $20^{\circ} 15^{\prime} \mathrm{S}$ e $43^{\circ} 30^{\prime} \mathrm{W}$. Os limites desta região são definidos por serras relacionadas a elementos estruturais. O limite norte é definido por estrutura invertida orientada segundo $N 70^{\circ} \mathrm{NE}$, denominado Serra do Curral; o limite oeste pela aba do sinclinal Moeda, Serra da Moeda; o sul pela Serra do Ouro Branco, bloco soerguido por falhamento e o limite este é menos preciso, incluindo parte da porção oeste do anticlinal de Mariana e o maciço do Caraça (ÂMBIO 1991). A geologia e a litoestratigrafia do Quadrilátero Ferrífero foram descritas por DNPM (1958) e Dorr (1969). O Pico de Itabirito é um raro exemplo de afloramento de hematita com 1.585,8 m de altitude (Teixeira 1997).

A área amostrada no presente estudo está inserida na depressão interna do sinclinal Moeda, cujas coordenadas geográficas centrais são $20^{\circ} 13^{\prime}$ $43^{\prime \prime}$ S e $43^{\circ} 51^{\prime} 39^{\prime \prime}$ W. Apresenta cotas superiores a $1300 \mathrm{~m}$, constituindo a Serra dos Inconfidentes uma elevação que divide a área amostrada, aproximadamente, no sentido norte - sul (Fig. 2). É caracterizada pela ocorrência generalizada de afloramentos rochosos associados a solos litólicos ao longo de toda a extensão de formações quartzíticas e itabiríticas capeadas por carapaças de canga. A grande maioria dos solos litólicos é distrófica, com carência generalizada de nutrientes (CERN 2006). Os solos litólicos distróficos são fortemente ácidos e apresentam valores médios de matéria orgânica. Junto às drenagens naturais, de relevo aplainado, ocorrem pequenas porções de solos hidromórficos, que podem apresentar espessa camada escura de matéria orgânica mal decomposta sobre camada acinzentada (gleisada). São solos geralmente distróficos ou álicos. A região é dominada pelo clima $\mathrm{Cwb}$, segundo a classificação de Köppen (CERN 2006), tropical de altitude com chuvas de verão, verões frescos e precipitação média acima de $1300 \mathrm{~mm}$ anuais.

A precipitação média anual, segundo dados de outubro de 1990 a fevereiro de 2005 é de $1581,6 \mathrm{~mm}$, 
A flórula rupestre do Pico de Itabirito, Minas Gerais, Brasil

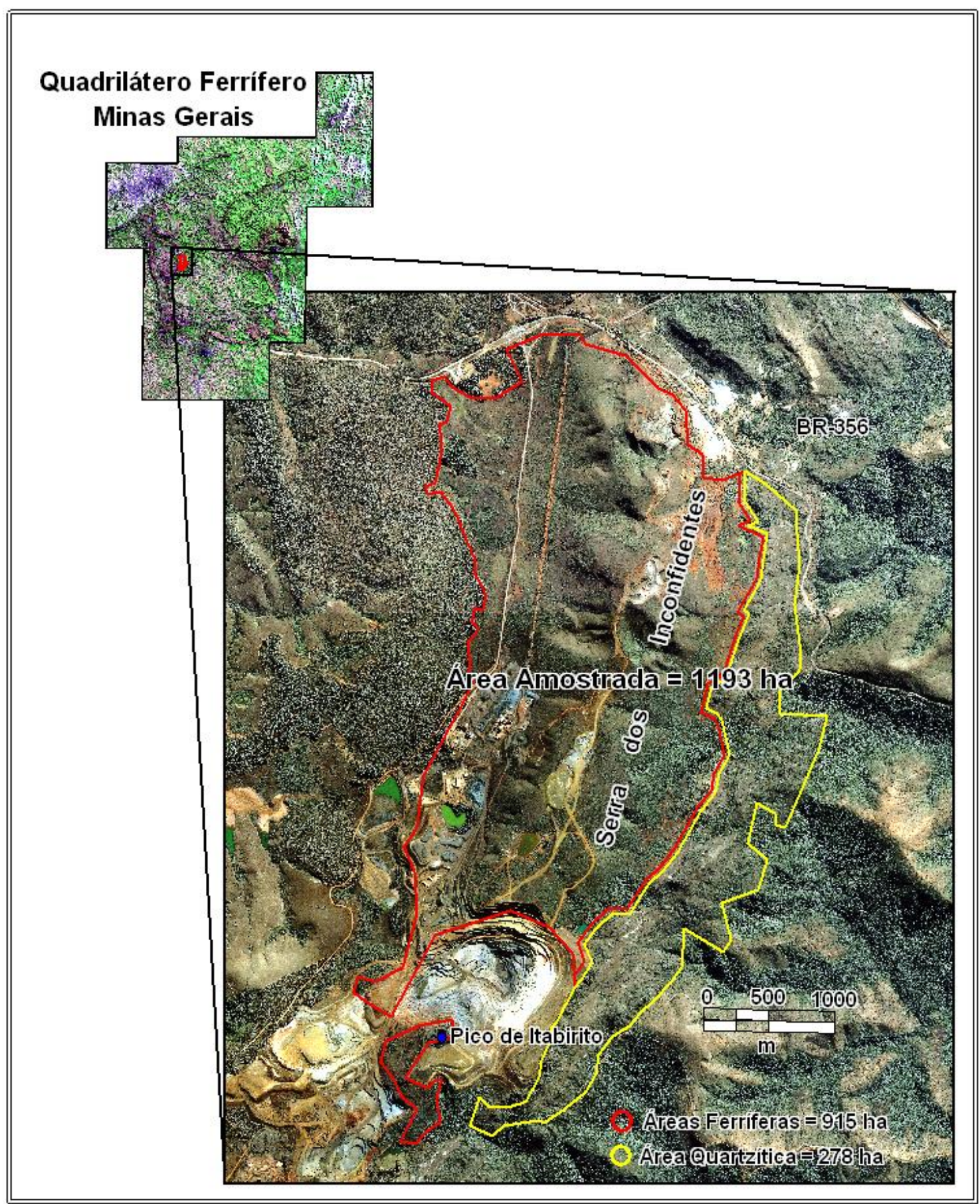

Fig. 2 - Área amostrada na região do Pico de Itabirito, Minas Gerais, Brasil. (Fonte: Google Earth) 
variando de uma mínima de 8,1 mm em julho e 357,1 em janeiro (CERN 2006). Os três meses mais secos são junho, julho e agosto e, os mais chuvosos, novembro, dezembro e janeiro (CERN 2006) (Fig. 3).

Os outros dados climatológicos foram obtidos na mina de Capão Chavier, que dista 18 km, em linha reta, a noroeste do Pico de Itabirito, colhidos no período entre maio de 1994 a dezembro de 1999 (com lacunas importantes de informação). A temperatura média anual é de $18,7^{\circ} \mathrm{C}$, com uma variação de $15,8^{\circ} \mathrm{C}$ em julho e $21,6^{\circ} \mathrm{C}$ em janeiro. A média das temperaturas mínimas anuais absolutas é de $9,1^{\circ} \mathrm{C}$, variando de $3,5^{\circ} \mathrm{C}$ no mês de agosto à $15,9^{\circ} \mathrm{C}$ no mês de janeiro. A média das temperaturas máximas anuais absolutas é de $30,0^{\circ} \mathrm{C}$, variando de $26^{\circ} \mathrm{C}$ no mês de maio à $34,1^{\circ} \mathrm{C}$ no mês de setembro (CERN 2006) (Fig. 4).

A umidade relativa do ar apresenta uma média anual de $79 \%$, consideravelmente alta. A média dos meses mais úmidos, janeiro e dezembro, é de $85 \%$ e, dos meses mais secos, agosto e setembro, $68 \%$ e $69 \%$, respectivamente. Entretanto, as mínimas absolutas são bastante baixas, ocasionando dias com déficit de saturação. A umidade mínima absoluta atinge valores de $15 \%$ em setembro e $16 \%$ em agosto (CERN 2006). As direções predominantes de entrada de ventos são $E$, NE e SE. As velocidades mais freqüentes se encontram entre 1,5 e $3,0 \mathrm{~m} / \mathrm{s}$, havendo esporádicas rajadas com velocidades superiores a 10 $\mathrm{m} / \mathrm{s}$ (CERN 2006).

A área amostrada (Fig. 2) apresenta, predominantemente, cobertura vegetal campestre associada à degradação quartzítica e ferrífera, denominada comumente campos rupestres. Nas drenagens naturais e encostas mais úmidas há ocorrência de florestas secundárias.

\section{Coletas botânicas e subseqüentes tratamentos}

As coletas botânicas foram realizadas por meio de caminhamento aleatório numa área de 1193 ha. Os ambientes ferríferos amostrados apresentam área de 915 ha e os quartzíticos, 278 ha. A maior parte do material foi coletado no período entre 1993 e 1996. Uma segunda etapa de coletas foi realizada entre 2003 e 2005. As coletas se restringiram às formações campestres e ecótonos, com predominância de substratos quartzíticos e ferríferos em altitude variando entre 1300 a $1550 \mathrm{~m}$. As áreas de coleta encontramse delimitadas na Fig. 2. Os espécimes foram herborizados segundo as técnicas usuais e encontram-se depositados no herbário da Universidade Federal de Minas Gerais (herbário BHCB). A identificação da maior parte do material foi realizada por estudiosos dos respectivos táxons, tendo sido consultados mais de setenta especialistas.

\section{Definição do sistema de classificação taxonômica e de categorias de ameaça}

A ordenação da lista florística reúne blocos da licófitas e monilófitas (Pteridophyta dos sistemas de classificação tradicionais), gimnospermas (com apenas uma espécie de Podocarpaceae) e angiospermas. Dentro de cada um desses blocos o ordenamento das famílias, gêneros e espécies segue a ordem alfabética. Para as samambaias e licófitas foi adotada a classificação de famílias constante em Smith et al. (2006, 2008) e Christenhusz et al. (2011). Para angiospermas foi adotada circunscrição de famílias do APG III (2009), adotada também por Souza \& Lorenzi (2012). Os binômios foram atualizados em concordância com os adotados na Lista de Espécies da Flora do Brasil edição 2012 (http://floradobrasil.jbrj.gov.br).

A categorização do status de ameça das espécies seguem as definições da Revisão da Lista das Espécies da Flora Ameaçadas de Extinção do Estado de Minas Gerais (FUNDAÇÃO BIODIVERSITAS 2012).

\section{Resultados e discussão}

\section{Aspectos da fitofisionomia do Pico de Itabirito e sua flora}

$\mathrm{Na}$ região do Pico de Itabirito, os ambientes florestais apresentam-se junto às drenagens naturais, estendendo-se pelos flancos das serras. Nas fraturas entre rochas, em que se formam bolsões de matéria orgânica, apresenta porte baixo, mas que tendem a ser mais desenvolvidos quando em situação edáfica favorável. As formações florestais são constituídas principalmente pelas florestas ciliares e de encosta. Não correspondem à formação original, mas sim a diferentes estágios de regeneração, visto que a maior parte das florestas da região foi objeto de exploração, desde 0 período colonial, para atender às necessidades da mineração aurífera. A região do Pico possui uma das minas que tiveram grande prestígio no século XIX, a mina de Cata Branca. O seu subsequente abandono proporcionou o surgimento de atividades econômicas ligadas à agricultura e pecuária, que resultaram em nova etapa de degradação das matas locais. Saint-Hilaire (1975), em viagem pelas províncias do Rio de Janeiro e Minas Gerais na primeira metade do século XIX, assim referiu-se à região do Quadrilátero Ferrífero: "desse modo, os agricultores terminam na Província das Minas o que começaram os homens que iam à cata do ouro, a funesta destruição das matas. A falta de lenha já se faz sentir em algumas vilas que foram provavelmente construídas no seio de florestas, e as minas de ferro, de riquíssimo teor em metal, não podem ser exploradas por falta de combustível". Kamino et al. (2008) mencionam que as perturbações nos ecossistemas florestais do Quadrilátero Ferrífero, iniciadas no século XVII, com a mineração aurífera, influenciaram significativamente as variações florísticas, constatadas em seu estudo sobre a fitofisionomia das florestas da Cadeia do Espinhaço. Por esse motivo, uma classificação fisionômica, com base nos remanescentes florestais atuais, certamente 
A flórula rupestre do Pico de Itabirito, Minas Gerais, Brasil

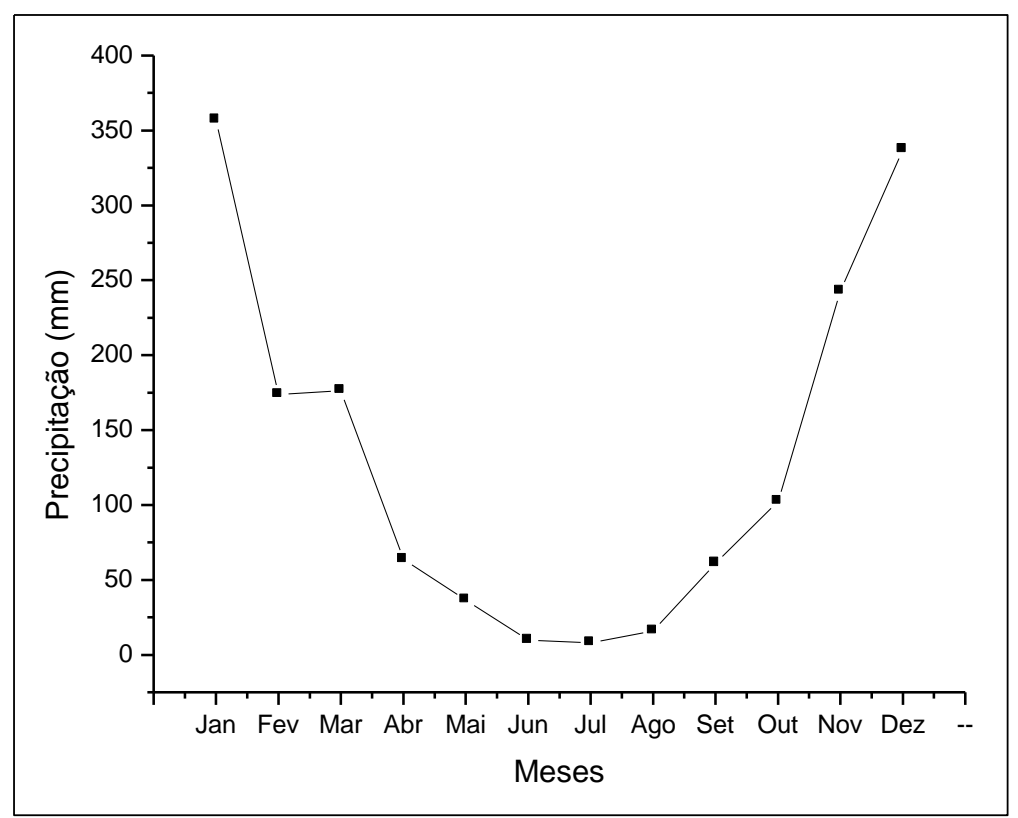

Fig. 3 - Variação temporal da precipitação anual, média de outubro de 1990 a fevereiro de 2005, Pico do Itabirito, Minas Gerais, Brasil.

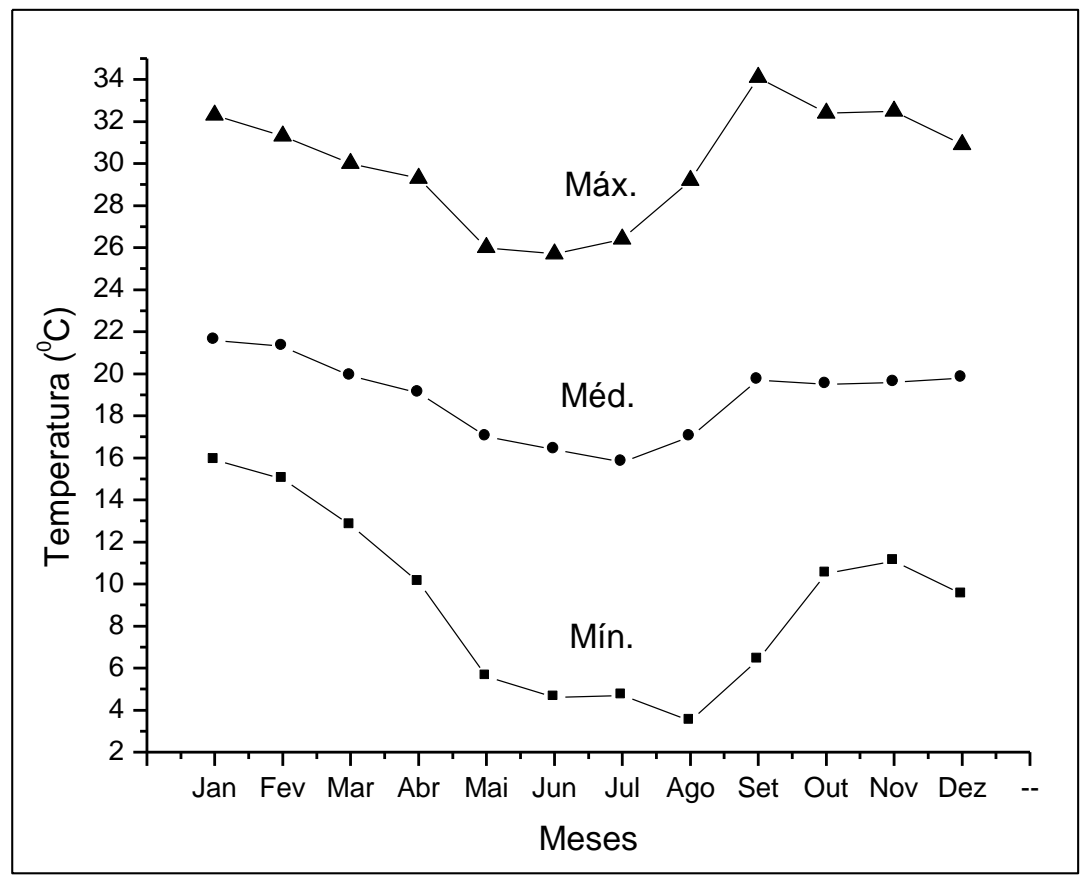

Fig. 4 - Temperaturas mínimas, médias e máximas do ar $\left({ }^{\circ} \mathrm{C}\right)$ - estação automática, Pico do Itabirito, Minas Gerais, Brasil. 
não proporcionará uma definição precisa, quanto ao clímace dessa formação.

Segundo os mapas de vegetação (IBGE 1993, Costa et al. 1998, PROBIO 2000), as formações florestais da região estariam inseridas nos domíniosdas florestas estacionais semideciduais. Contudo, em alguns sítios locais, geralmente em cotas altas e junto às drenagens naturais, há ocorrência de encraves florestais sempre-verdes. Este tipo de formação florestal montana, encontrado ao longo da Cadeia do Espinhaço, tem sido tratado como matas nebulares (Giulietti et al. 1987, Harley 1995, Pirani et al. 2003, Zappi et al. 2003). As fisionomias florestais locais, independentemente do grau de deciduidade foliar, comumente são enquadradas dentro dos domínios da Mata Atlântica (IBGE 1993). Entre os táxons mais comuns às florestas da região do Pico de Itabirito, famílias com respectivos gêneros, tem-se: Podocarpaceae (Podocarpus), Annonaceae (Guatteria, Xylopia), Urticaceae (Cecropia), Hypericaceae (Vismia), Euphorbiaceae (Croton), Leguminosae (Anadenanthera, Copaifera, Machaerium, Piptadenia, Sclerolobium, Senna), Lauraceae (Ocotea), Malpighiaceae (Byrsonima), Melastomataceae (Miconia, Tibouchina), Myrsinaceae (Rapanea), Myrtaceae (Calyptranthes, Myrcia), Malvaceae (Luehea), Vochysiaceae (Vochysia). Nos ambientes florestais de acesso mais difícil, encontramse as árvores mais antigas e aí se observa maior abundância e diversidade de epífitas, principalmente das famílias Araceae, Bromeliaceae, Cactaceae, Orchidaceae, Piperaceae e Polypodiaceae.

Os ambientes campestres constituem uma tipologia com ampla circunscrição local, apresentando grande variação na estrutura e composição florística. $\mathrm{Na}$ transição entre as áreas de fisionomia puramente campestre para aquelas onde se desenvolve vegetação lenhosa mais adensada e de maior porte há também uma variação na composição entre as populações herbáceo-subarbustiva e arbustivoarbórea. Assim, quando um desses componentes se acha bem representado numa comunidade, o outro tende a desaparecer, tal como descrito por Coutinho (1978) em relação aos cerrados. Estando em uma região de interface entre biomas, verifica-se uma variada interposição entre vegetais, geralmente, associados a ambientes distintos. Assim, espécies que tipificam os cerrados, tais como Stryphnodendron adstringens, Bowdichia virgilioides, Vochysia thyrsoidea, Myrsine umbellata, se mesclam à vegetação rupestre, conformando mosaicos vegetacionais bastante complexos e muitas vezes de difícil separação (Eiten 1972, Rodela 1998, Pirani et al. 2003).

Nas áreas ferríferas amostradas, sobre a Serra dos Inconfidentes e suas encostas predominam os campos ferruginosos (Rizzini 1979), também denominados de vegetação de canga (Secco \& Mesquita 1983, Morelato \& Rosa 1991, Silva 1991, 1992). Rizzini (1979) separou este ambiente em campos ferruginosos de canga couraçada e de canga nodular. Geralmente, na canga couraçada desenvolve- se uma vegetação mais rarefeita, tornando-se mais fechada (densa) e de maior porte, à medida que o substrato apresenta-se mais friável. Algumas espécies são particularmente endêmicas a esse substrato. Entre estas, Lychnophora pinaster, Arthrocereus glaziovii, Sinningia rupicola, Mimosa calodendron, Hoffmannseggella caulescens, Vellozia virgata. No flanco oeste desta Serra, em que os substratos também são ferruginosos, é expressiva a vegetação que se desenvolve nas depressões alagáveis (comunidades aluviais). Nestas áreas, conforme a quantidade de água empoçada e ainda o tempo de sua permanência, as comunidades vegetais vão desde a pantanosa, com a presença de espécies de Cyperaceae, Typha angustifolia, Utricularia spp., ocupando pequenas extensões, até os terraços alagáveis temporariamente, em que predominam representantes das famílias Burmanniaceae, Cyperaceae, Eriocaulaceae, Poaceae, Xyridaceae, Droseraceae, Onagraceae, entre outras.

A leste da Serra dos Inconfidentes desenvolvem-se os campos rupestres associados à alteração de quartzitos. Com relação à composição qualitativa de sua flora, verifica-se que um grande número de táxons são comuns àqueles presentes nos campos ferruginosos, constituindo as maiores diferenças, principalmente, quanto à fitofisionomia. As áreas quartzíticas amostradas somam 278 ha (Fig. 2). Menezes \& Giulietti (1986) caracterizam essa formação como sendo constituída por um estrato herbáceo mais ou menos contínuo e por arbustos ou subarbustos esparsos, esclerofilos, sempre-verdes, frequentemente com folhas imbricadas ou em roseta, sendo comum essa convergência morfológica a várias famílias. No entanto, essa caracterização não foi concebida com ensejo de homogeneizar os campos rupestres quartzíticos, cujas associações estão condicionadas a fatores ambientais locais (Giulietti et al. 2000), o que propicia o desenvolvimento de fisionomias bastante heterogêneas (Pereira 1994, Vitta 1995, Conceição \& Giulietti 2002, Conceição \& Pirani 2007). Na região do Pico do Itabirito, nos locais que apresenta microtopografia aplainada e solos arenosos ou areno-argilosos, geralmente, predominam uma formação curtigraminosa com poucas árvores de pequeno porte de ocorrência espaçada. Sobre esta composição, comunidades diferenciadas se manisfestam, por exemplo, formações mais ou menos uniformes de Actinocephalus bongardii, Microlicia crenulata, M. fasciculata, M. isophylla e Diplusodon buxifolius. À medida que o substrato apresenta-se cascalhento surgem espécies tais como Bulbostylis paradoxa, Duguetia furfuracea, Sinningia allagophylla e Vellozia compacta. Nos locais sujeitos a encharcamentos periódicos, ou próximos aos cursos d'água, são comuns Trimezia juncifolia, Paepalanthus elongatus, P. flaccidus, Syngonanthus anthemidiflorus, Habenaria caldensis, $H$. humilis, Drosera montana. Onde despontam os afloramentos quartzíticos, desenvolve-se uma vegetação lenhosa mais expressiva, sendo predominantes principalmente Guatteria villosissima, Schefflera lucumoides, 
A flórula rupestre do Pico de Itabirito, Minas Gerais, Brasil

Baccharis platypoda, Eremanthus glomerulatus, Trembleya laniflora, Siphoneugena densiflora.

Seguramente a grande maioria dos ambientes da região do Pico de Itabirito já passou por algum processo de interferência humana. Em ambos os flancos da Serra dos Inconfidentes são comuns as ocorrências de povoamentos quase puros de candeia (Eremanthus erythropappus), em áreas transicionais entre as formações campestres e florestas de galeria ou de encosta. Oliveira-Filho \& Fluminhan-Filho (1999) denominaram esse ambiente como candeal. Segundo esses autores, esta formação está associada à presença de solos rasos e pode ter o regime de incêndios como principal determinador de seus limites de ocorrência. Na região do Pico de Itabirito, esta expressão vegetacional certamente está relacionada à derrubada das florestas locais, não se excluindo outros fatores antrópicos necessários à sua manutenção. Algumas vezes há um consórcio entre esta espécie e Eremanthus glomerulatus. Porém, em relação à ocorrência destas espécies, um aspecto pode ser constatado. Os ambientes colonizados por $E$. erythropappus tendem a possuir condições edáficas mais favoráveis, maior friabilidade e maiores teores de matéria orgânica. Os ambientes colonizados por $E$. glomerulatus apresentam-se mais inóspitos, com as espécies se interpondo onde os fatores edáficos apresentam-se intermediários.

A descrição aqui apresentada constitui apenas uma sinopse da realidade vegetacional e florística da região do Pico de Itabirito. De fato há naturalmente grande dificuldade para a separação e distinção da vegetação local que apresenta fisionomias bastante variáveis e fases intermediárias.

O levantamento da região do Pico de Itabirito produziu uma listagem com 722 espécies identificadas no nível específico, distribuídas em 100 famílias e 384 gêneros (tabela 1). As dez principais famílias em número de espécies contribuem com $57 \%$ da lista apresentada. Apenas as quatro famílias mais ricas, Asteraceae, Orchidaceae, Melastomataceae e Leguminosae respondem por cerca de $35 \%$ do número total de espécies. Entre as espécies do Pico de Itabirito, 47 constam da Revisão da Lista das Espécies da Flora Ameaçadas de Extinção do Estado de Minas Gerais (Fundação Biodiversitas 2012) e corresponde a $6,49 \%$ do total de espécies amostradas. Esse número está distribuído nas seguintes categorias: vulnerável (27 spp.), em perigo (14 spp.) e criticamente em perigo (6 spp.) e corresponde a 4,17 \% desta lista, que possui 1127 espécies.

Em comparação com as espécies registradas no herbário BHCB, que conta com mais de 110.000 espécimes, pelo menos 10 são esclusivas do Pico de Itabirito, em sua maior parte incluídas nas famílias Apocynaceae, Asteraceae, Orchidaceae e Melastomataceae. Vários estudos vêm demonstrando que os campos rupestres constituem um sistema bastante heterogêneo, com contrastes fisionômicos e de composição florística em curtos espaços (Conceição 2000, 2003, Conceição \& Giulietti 2002, Conceição \& Pirani 2005, 2007, Stehmann \& Mourão
2007). Dessa forma é bem provável que o Quadrilátero Ferrífero, em particular, também apresente uma descontinuidade botânica ao longo de sua extensão. Isto torna os sítios de ocorrência de campos rupestres dentro dessa região importantes do ponto de vista conservacionista. Nesse sentido, verifica-se a ocorrência restrita de algumas espécies: Hoffmannseggella milleri (Blumensch. ex Pabst) V.P.Castro \& Chiron e Brasilidium marshallianum (Rchb. f.) Campacci, na região do Belo Vale, Brasilidium forbesii (Hook.) Campacci, na região de Nova União (região periférica do Quadrilátero Ferrífero). Na área amostrada da região do Pico de Itabirito há ocorrências pontuais de algumas espécies e, caso esses locais sejam degradados, há sério risco de extinção local. Nessa situação enquadram-se: Philodice hoffmannseggii, Lavoisiera imbricata, Physocalyx major, Syagrus petrea, Minaria monocoronata, Elleanthus brasiliensis, E. crinipes, Brasilidium crispum, Coppensia hydrophila, Habenaria edwallii, Hadrolaelia pumila, Hoffmannseggella liliputana, esta última provavelmente já extinta em decorrência da atividade mineratória. Ditassa monocoronata é espécie com escassas coletas nos últimos 50 anos. Alessandro Rapini (com. pess.) em recente expedição à área do Pico de Itabirito não a encontrou, considerando que pode estar extinta localmente. Philodice hoffmnnseggi é importante do ponto de vista biogeográfico, pois pertence a um gênero composto por apenas dois táxons, com ocorrência disjunta, entre o Brasil e Venezuela (Coan et al. 2002), não se conhecendo publicações que a tenham citado anteriormente para o Quadrilátero Ferrífero de Minas Gerais.

Além da ocorrência pontual das espécies restritas, deve-se ter em conta o número de indivíduos presentes nas populações. Romero \& Nakajima (1999), em estudo sobre espécies endêmicas do Parque Nacional da Serra da Canastra, Minas Gerais, observaram que algumas espécies com distribuição restrita podem ser comuns localmente, enquanto que outras são extremamente raras. No trabalho de Costa et al. (1998), sobre áreas prioritárias para conservação no estado de Minas Gerais, o Quadrilátero Ferrífero foi enquadrado como região de "importância biológica extrema”. O Pico de Itabirito, como parte dessa região, apresenta uma composição florística que merece atenção quanto a medidas conservacionistas.

Considerando que: 1 . os campos rupestres constituem importantes centros de diversidade e endemismos da flora brasileira (e.g. Giulietti et al. 1997); 2. entre os critérios para determinar áreas potenciais para conservação, o grau de endemismo e raridade deve ser levado em consideração (Kruckeberg \& Rabinowitz 1985, Gentry 1986); 3. a priorização de áreas de conservação dos campos rupestres deve incluir a maior riqueza de espécies na área, o maior número de táxons endêmicos e também a maior diversidade possível de tipos de vegetação associados (como matas nebulares, matas deciduais, Cerrado, Caatinga - Zappi et al. 2003); 4. a maioria das espécies de campo rupestre é rara, seja pela distribuição restrita 
ou pela baixa frequência (Conceição et al. 2005); os dados da presente flórula rupestre do Pico de Itabirito, diversificada e com presença de muitas das espécies conhecidas como endêmicas da Cadeia do Espinhaço ou apenas de suas áreas mais meridionais, associados às especificidades de habitats ocupados por muitas das espécies rupestres documentadas, permite-nos afirmar que a remoção dos substratos rochosos pode ocasionar a depleção de sua diversidade local e que a proteção dessa área é necessária para a conservação de sua rica biota.

Tabela 1 - Lista de espécies vasculares do Pico de Itabirito, Minas Gerais, Brasil, acompanhadas de citação de um material-testemunho selecionado (no. de registro no herbário BHCB), e discriminando formas de vida, hábitos, habitats e categorias de ameaça em Minas Gerais. Legenda: formas de vida (Herbácea, Arbustiva, Arborescente, Arvoreta (árvores que comumente não ultrapassam $3 \mathrm{~m}$ alt.), Arbórea, liana herbácea = Lian. Herb., liana lenhosa $=$ Lian. Lenh., Cespitosa), hábito (terrestre $=T$, aquática $=A$, saxícola $=S$, rupícola $=R$, epífita $=\mathrm{E}$, hemiparasita $=\mathrm{H}$, parasita $=\mathrm{P}$ ), ambiente (canga $=\mathrm{C}$, quartzito $=\mathrm{Q}$, transição para floresta $=\mathrm{TF}$, ambiente antrópico $=\mathrm{AA}$ ), categoria de ameaça (vulnerável $=\mathrm{VU}$, em perigo $=\mathrm{EN}$, criticamente em perigo $=\mathrm{CR}$ ).

\begin{tabular}{|c|c|c|c|c|c|}
\hline GRUPOS/ FAMÍLIAS/ Espécies & № ВНСВ & $\begin{array}{c}\text { Forma de } \\
\text { vida }\end{array}$ & Hábito & Ambiente & $\begin{array}{l}\text { Categoria de } \\
\text { ameaça (MG) }\end{array}$ \\
\hline \multicolumn{6}{|l|}{ LICÓFITAS } \\
\hline \multicolumn{6}{|l|}{ LYCOPODIACEAE } \\
\hline Huperzia reflexa (Lam.) Trevis. & 10948 & Herbácea & $\mathrm{T}$ & Q & \\
\hline Lycopodiella alopecuroides (L.) Cranfill & 10950 & Herbácea & S & $C / Q$ & \\
\hline Lycopodiella caroliniana (L.) Pic.Serm. & 17406 & Herbácea & $T$ & C & \\
\hline Lycopodiella cernua (L.) Pic.Serm. & 10949 & Herbácea & $S$ & Q & \\
\hline Lycopodium clavatum L. & 10947 & Herbácea & $T$ & $C / Q$ & \\
\hline \multicolumn{6}{|l|}{ MONILÓFITAS } \\
\hline \multicolumn{6}{|l|}{ ANEMIACEAE } \\
\hline Anemia glareosa Gardner & 94860 & Herbácea & $\mathrm{T}$ & Q & VU \\
\hline Anemia lanuginosa Bong.ex J.W.Sturm & 11020 & Herbácea & $\mathrm{S}$ & $Q$ & \\
\hline Anemia villosa Humb. \& Bonpl. ex Willd. & 11023 & Herbácea & $T$ & $Q$ & \\
\hline \multicolumn{6}{|l|}{ ASPLENIACEAE } \\
\hline Asplenium auritum $\mathrm{Sw}$. & 94859 & Herbácea & S & $Q$ & \\
\hline Asplenium serra Langsd. \& Fisch. & 94862 & Herbácea & $\mathrm{S} / \mathrm{R}$ & $\mathrm{C}$ & \\
\hline \multicolumn{6}{|l|}{ BLECHNACEAE } \\
\hline Blechnum confluens Schlecht. \& Cham. & 10964 & Herbácea & $S$ & C & \\
\hline Blechnum polypodioides Raddi & 10965 & Herbácea & $\mathrm{T}$ & $C-A A$ & \\
\hline \multicolumn{6}{|l|}{ CYATHEACEAE } \\
\hline Cyathea delgadii Sternb. & 10961 & Arbores. & $\mathrm{T}$ & C & \\
\hline Cyathea villosa Willd. & 10962 & Arbores. & $\mathrm{T}$ & $C / Q$ & \\
\hline \multicolumn{6}{|l|}{ DENNSTAEDTIACEAE } \\
\hline Pteridium arachnoideum (Kaulf.) Maxon & 10966 & Herbácea & $\mathrm{T}$ & Q & \\
\hline \multicolumn{6}{|l|}{ DRYOPTERIDACEAE } \\
\hline Arachniodes denticulata (Sw.) Ching & 23929 & Herbácea & S & C & \\
\hline Elaphoglossum actinotrichum (Mart.) T.Moore & 28493 & Herbácea & $S / R$ & Q - TM & \\
\hline Elaphoglossum burchellii (Baker) C.Chr. & 28491 & Herbácea & $S / R$ & $Q-T M$ & \\
\hline Elaphoglossum gayanum (Fée) T.Moore & 94863 & Herbácea & $\mathrm{S}$ & C & \\
\hline Elaphoglossum glabellum J.Sm. & 27837 & Herbácea & $S / R$ & Q & \\
\hline Elaphoglossum sellowianum (Pr.) & 28492 & Herbácea & $S / R$ & Q - TM & \\
\hline Rumohra adiantiformis (G.Forst.) Ching & 24266 & Herbácea & S & C & \\
\hline
\end{tabular}


A flórula rupestre do Pico de Itabirito, Minas Gerais, Brasil

\begin{tabular}{|c|c|c|c|c|c|}
\hline GLEICHENIACEAE & & & & & \\
\hline Dicranopteris flexuosa (Schrad.) Underw. & 24076 & Herbácea & $\mathrm{T}$ & $C-A A$ & \\
\hline Sticherus penniger (Mart.) Ching & 10952 & Herbácea & $\mathrm{T}$ & Q & \\
\hline \multicolumn{6}{|l|}{ LINDSAEACEAE } \\
\hline Lindsaea stricta (Sw.) Dryand. & 23969 & Herbácea & $\mathrm{T}$ & Q & \\
\hline \multicolumn{6}{|l|}{ OSMUNDACEAE } \\
\hline Osmunda regalis $\mathrm{L}$. & 10975 & Herbácea & $\mathrm{T}$ & $\mathrm{C}$ & \\
\hline \multicolumn{6}{|l|}{ POLYPODIACEAE } \\
\hline $\begin{array}{l}\text { Lellingeria apiculata (Kunze ex Klotzsch) A.R.Sm. \& } \\
\text { R.C.Moran }\end{array}$ & 10954 & Herbácea & $S / R$ & $C / Q$ & \\
\hline Microgramma squamulosa (Kaulf.) de la Sota & 27842 & Herbácea & $\mathrm{R} / \mathrm{E}$ & C / Q - TM & \\
\hline Pecluma pectinatiformis (Lindm.) M.G.Price & 10953 & Herbácea & $\mathrm{R} / \mathrm{E}$ & Q & \\
\hline Phlebodium aureum (L.) J.Sm. & 27836 & Herbácea & $\mathrm{R} / \mathrm{E}$ & $C / Q$ & \\
\hline Pleopeltis hirsutissima (Raddi) de la Sota & 24265 & Herbácea & $\mathrm{S}$ & $\mathrm{C}$ & \\
\hline Serpocaulon catharinae (Langsd. \& Fisch.) A.R.Sm. & 27838 & Herbácea & $\mathrm{R} / \mathrm{E}$ & $\mathrm{C}$ & \\
\hline \multicolumn{6}{|l|}{ PTERIDACEAE } \\
\hline Adiantum subcordatum Sw. & 10956 & Herbácea & S & Q & \\
\hline Doryopteris collina (Raddi) J.Sm. & 10957 & Herbácea & S & C - TM & \\
\hline Doryopteris lomariacea Klotzsch & 10958 & Herbácea & $\mathrm{T}$ & $\mathrm{C}$ & \\
\hline Doryopteris ornithopus (Hook. \& Baker) J.Sm. & 10959 & Herbácea & S & Q & \\
\hline Cheilanthes eriophora (Fée) Mett. & 10960 & Herbácea & $\mathrm{T}$ & C & \\
\hline Pellaea crenata R.M. Tryon & 94861 & Herbácea & S & Q & \\
\hline Pellaea pinnata (Kaulf.) Prantl & 27843 & Herbácea & $\mathrm{T}$ & Q & \\
\hline Pteris vittata $\mathrm{L}$. & 10955 & Herbácea & $\mathrm{S} / \mathrm{R}$ & $C / Q$ & \\
\hline \multicolumn{6}{|l|}{ THELYPTERIDACEAE } \\
\hline Thelypteris rivularioides (Fée) Abbiatti & 11097 & Herbácea & $\mathrm{T}$ & $\mathrm{C}$ & \\
\hline \multicolumn{6}{|l|}{ GIMNOSPERMA } \\
\hline \multicolumn{6}{|l|}{ PODOCARPACEAE } \\
\hline Podocarpus sellowii Klotzsch ex Endl. & 25017 & Arbórea & $S$ & $Q$ & \\
\hline \multicolumn{6}{|l|}{ ANGIOSPERMAS } \\
\hline \multicolumn{6}{|l|}{ ACANTHACEAE } \\
\hline Justicia monticola (Nees) Profice & 26522 & Herbácea & $T$ & $Q$ & \\
\hline Justicia riparia Kameyama & 22045 & Arbustiva & $\mathrm{T}$ & C - TM & \\
\hline Ruellia geminiflora Kunth & 90566 & Arbustiva & $\mathrm{T}$ & C & \\
\hline Ruellia macrantha (Mart. ex Nees) Lindau & 26525 & Herbácea & $T$ & Q - TM & \\
\hline Ruellia villosa (Nees) Lindau & 22140 & Arbustiva & $\mathrm{T}$ & Q & \\
\hline Staurogyne ericoides Lindau & 25204 & Herbácea & $\mathrm{T}$ & $C / Q$ & \\
\hline \multicolumn{6}{|l|}{ ALSTROEMERIACEAE } \\
\hline Alstroemeria plantaginea Mart. ex Schult. \& Schult.f. & 24247 & Herbácea & $\mathrm{S} / \mathrm{T}$ & C & EN \\
\hline \multicolumn{6}{|l|}{ AMARANTHACEAE } \\
\hline Alternanthera brasiliana (L.) Kuntze & 25061 & Herbácea & $\mathrm{T}$ & C & \\
\hline Gomphrena agrestis Mart. & 26065 & Arbustiva & $\mathrm{T}$ & Q & \\
\hline Gomphrena arborescens L.f. & 24068 & Arbustiva & $\mathrm{T}$ & C & \\
\hline Gomphrena lanigera Pohl ex Moq. & 24257 & Arbustiva & $\mathrm{T}$ & Q & \\
\hline Gomphrena rudis Moq. & 25138 & Herbácea & $T$ & Q & \\
\hline
\end{tabular}




\begin{tabular}{|c|c|c|c|c|c|}
\hline Gomphrena scapigera Mart. & 22048 & Arbustiva & $T$ & $Q$ & \\
\hline Gomphrena virgata Mart. & 25090 & Arbustiva & $\mathrm{T}$ & Q & \\
\hline Pfaffia jubata Mart. & 22179 & Arbustiva & $T$ & $Q$ & \\
\hline \multicolumn{6}{|l|}{ AMARYLIDACEAE } \\
\hline Habranthus irwinianus Ravenna & 24463 & Herbácea & $S / T$ & $\mathrm{C}$ & VU \\
\hline Hippeastrum morelianum Lem. & 24462 & Herbácea & $S$ & $C / Q$ & VU \\
\hline \multicolumn{6}{|l|}{ ANACARDIACEAE } \\
\hline Lithraea molleoides (Vell.) Engl. & 94846 & Arbórea & $T$ & $C / Q$ & \\
\hline \multicolumn{6}{|l|}{ ANNONACEAE } \\
\hline Annona monticola Mart. & 26160 & Arbustiva & $T$ & $\mathrm{C} / \mathrm{Q}$ & \\
\hline Annona warmingiana Mello-Silva \& Pirani & 94855 & Arbustiva & $T$ & $C-A A$ & \\
\hline Duguetia furfuraceae (A.St.-Hil.) Saff. & 26041 & Arbustiva & $\mathrm{T}$ & $C / Q$ & \\
\hline Guatteria sellowiana Schltdl. & 90568 & Arbórea & $\mathrm{T}$ & C - TM & \\
\hline Guatteria villosissima A.St.-Hil. & 26132 & Arbórea & $T$ & C / Q - TM & \\
\hline \multicolumn{6}{|l|}{ APIACEAE } \\
\hline Eryngium canaliculatum Cham. \& Schltdl. & 25129 & Herbácea & $\mathrm{T}$ & Q & \\
\hline Eryngium ebracteatum Lam. & 26370 & Herbácea & $\mathrm{T}$ & $\mathrm{C}$ & \\
\hline Eryngium eurycephalum Malme & 24249 & Herbácea & $T$ & Q & \\
\hline Eryngium junceum Cham. \& Schltdl. & 26063 & Herbácea & $T$ & $Q$ & \\
\hline Eryngium sanguisorba Cham. \& Schltdl. & 26359 & Herbácea & $T$ & Q & \\
\hline Klotzschia brasiliensis Cham. & 26307 & Herbácea & $\mathrm{T}$ & $Q$ & \\
\hline \multicolumn{6}{|l|}{ APOCYNACEAE } \\
\hline Barjonia erecta (Vell.) K.Schum. & 23922 & Herbácea & $\mathrm{T}$ & Q & \\
\hline Blepharodon ampliflorum E.Fourn. & 24078 & Lian. Herb. & $\mathrm{T}$ & $C / Q$ & \\
\hline Blepharodon pictum (Vahl) W.D.Stevens & 23959 & Lian. Herb. & $\mathrm{T}$ & Q & \\
\hline Ditassa longisepala (Hua) Fontella \& E.A.Schwarz & 26241 & Lian. Herb. & $S / T$ & Q & VU \\
\hline Ditassa mucronata Mart. & 23934 & Lian. Herb. & $\mathrm{T}$ & $\mathrm{C}$ & \\
\hline Ditassa pedunculata Malme & 24106 & Herbácea & $\mathrm{S}$ & $Q$ & EN \\
\hline Ditassa retusa Mart. & 24246 & Lian. Herb. & S & Q & \\
\hline Forsteronia glabrescens Müll.Arg. & 26260 & Lian. Herb. & $\mathrm{S}$ & Q - TM & \\
\hline Hemipogon carassensis (Malme) Rapini & 24005 & Lian. Herb. & $\mathrm{T}$ & $\mathrm{C}$ & \\
\hline Mandevilla martiana (Stadelm.) Woodson & 24072 & Lian. Lenh. & $T$ & $Q$ & \\
\hline Mandevilla pohliana (Stadelm.) A.H.Gentry & 26503 & Herbácea & $\mathrm{T}$ & Q & \\
\hline Mandevilla tenuifolia (J.C.Mikan) Woodson & 24116 & Herbácea & $S$ & $\mathrm{C}$ & \\
\hline Mandevilla velame (A.St.-Hil.) Pichon & 26355 & Herbácea & $\mathrm{T}$ & Q & \\
\hline Matelea pedalis (E.Fourn.) Fontella \& E.A.Schwarz & 25013 & Lian. Herb. & $\mathrm{T}$ & Q & \\
\hline Minaria acerosa (Mart.) T.U.P.Konno \& Rapini & 25016 & Herbácea & $T$ & $Q$ & \\
\hline Minaria decussata (Mart.) T.U.P.Konno \& Rapini & 25015 & Herbácea & $T$ & Q & \\
\hline Minaria monocoronata (Rapini) T.U.P.Konno \& Rapini & 25014 & Lian. Herb. & $S / T$ & $C-A A$ & EN \\
\hline Oxypetalum appendiculatum Mart. & 23976 & Lian. Herb. & $T$ & $\mathrm{C}$ & EN \\
\hline Oxypetalum erectum Mart. & 24064 & Herbácea & $\mathrm{T}$ & $\mathrm{C}$ & \\
\hline Oxypetalum foliosum Mart. & 26175 & Herbácea & $\mathrm{T}$ & Q & \\
\hline Oxypetalum minarum E.Fourn. & 24091 & Herbácea & $\mathrm{T}$ & Q & VU \\
\hline Oxypetalum strictum Mart. & 21762 & Herbácea & $\mathrm{T}$ & Q & \\
\hline Oxypetalum wightianum Hook. \& Arn. & 94847 & Lian. Herb. & $\mathrm{T}$ & C - TM & \\
\hline
\end{tabular}


A flórula rupestre do Pico de Itabirito, Minas Gerais, Brasil

\begin{tabular}{|c|c|c|c|c|c|}
\hline \multicolumn{6}{|l|}{ AQUIFOLIACEAE } \\
\hline Ilex dumosa Reissek & 26310 & Arbustiva & $\mathrm{T}$ & $\mathrm{C}$ & \\
\hline Ilex subcordata Reissek & 26137 & Arbustiva & $\mathrm{T}$ & $C / Q$ & \\
\hline \multicolumn{6}{|l|}{ ARACEAE } \\
\hline Anthurium minarum Sakur. \& Mayo & 26242 & Herbácea & $S / R$ & Q & \\
\hline Monstera adansonii Schott & 26243 & Herbácea & $\mathrm{R} / \mathrm{E}$ & Q - TM & \\
\hline \multicolumn{6}{|l|}{ ARALIACEAE } \\
\hline Hydrocotyle quinqueloba var. glabra Cham. \& Schltdl. & 25065 & Lian. Herb. & $\mathrm{T}$ & C - TM & \\
\hline $\begin{array}{l}\text { Schefflera lacunoides (Decne. \& Planch. ex Marchal) } \\
\text { Frodin \& Fiaschi }\end{array}$ & 26039 & Arbustiva & $\mathrm{T}$ & $C / Q$ & VU \\
\hline \multicolumn{6}{|l|}{ ARECACEAE } \\
\hline Syagrus petraea (Mart.) Becc. & 94858 & Cespitosa & $\mathrm{T}$ & C & \\
\hline \multicolumn{6}{|l|}{ ARISTOLOCHIACEAE } \\
\hline Aristolochia smilacina (Klotzsch) Duch. & 23336 & Herbácea & $\mathrm{S} / \mathrm{T}$ & Q & \\
\hline \multicolumn{6}{|l|}{ ASTERACEAE } \\
\hline Achyrocline satureioides (Lam.) DC. & 25265 & Herbácea & $\mathrm{T}$ & $C / Q$ & \\
\hline Ageratum conyzoides $\mathrm{L}$. & 94844 & Herbácea & $\mathrm{T}$ & Q & \\
\hline Ageratum fastigiatum (Gardner) R.M.King \& H.Rob. & 23920 & Herbácea & $\mathrm{T}$ & $C / Q$ & \\
\hline Aspilia foliacea (Spreng.) Baker & 23457 & Arbustiva & $\mathrm{T}$ & Q & \\
\hline Aspilia fruticosa (Gardner) Baker & 25007 & Arbustiva & $\mathrm{T}$ & Q & \\
\hline Ayapana amygdalina (Lam.) R.M.King \& H.Rob. & 25292 & Arbustiva & $\mathrm{T}$ & Q & \\
\hline Baccharis aphylla (Vell.) DC. & 24990 & Arbustiva & $T$ & Q & \\
\hline Baccharis calvescens DC. & 90643 & Arbustiva & $\mathrm{T}$ & $C / Q$ & \\
\hline Baccharis crispa Spreng. & 25136 & Arbustiva & $\mathrm{T}$ & $C / Q$ & \\
\hline Baccharis dentata (Vell.) G.M.Barroso & 94852 & Arbustiva & $\mathrm{T}$ & Q - TM & \\
\hline Baccharis helichrysoides DC. & 26157 & Arbustiva & $\mathrm{T}$ & $C / Q$ & \\
\hline Baccharis ligustrina DC. & 25282 & Arbustiva & $\mathrm{T}$ & Q & \\
\hline Baccharis lychnophora Gardner & 25122 & Arbustiva & $\mathrm{T}$ & Q & EN \\
\hline Baccharis platypoda DC. & 25010 & Arbustiva & $T$ & $C / Q$ & \\
\hline Baccharis reticularia DC. & 24996 & Arbustiva & $T$ & $C-A A$ & \\
\hline Baccharis retusa DC. & 24989 & Arbustiva & $T$ & $Q$ & \\
\hline Baccharis serrulata (Lam.) Pers. & 25106 & Arbustiva & $\mathrm{T}$ & Q & \\
\hline Baccharis singularis (Vell.) G.M.Barroso & 25200 & Arbustiva & $T$ & $C-A A$ & \\
\hline Baccharis subdentata DC. & 25114 & Arbustiva & $\mathrm{T}$ & Q & \\
\hline Baccharis xiphophylla Baker & 25108 & Arbustiva & $T$ & $\mathrm{C}$ & \\
\hline Bidens segetum Mart. ex Colla & 94840 & Arbustiva & $T$ & $\mathrm{C}$ & \\
\hline Calea clausseniana Baker & 24118 & Arbustiva & $\mathrm{T}$ & Q & VU \\
\hline Calea rotundifolia (Less.) Baker & 24065 & Arbustiva & $\mathrm{T}$ & Q & VU \\
\hline $\begin{array}{l}\text { Campuloclinium megacephalum (Mart. ex Baker) } \\
\text { R.M.King \& H.Rob. }\end{array}$ & 23975 & Arbustiva & $\mathrm{T}$ & C & \\
\hline $\begin{array}{l}\text { Campuloclinium purpurascens (Sch.Bip. ex Baker) } \\
\text { R.M.King \& H.Rob. }\end{array}$ & 28496 & Arbustiva & $\mathrm{T}$ & Q & \\
\hline Chaptalia martii (Baker) Zardini & 25192 & Herbácea & $\mathrm{T}$ & Q & EN \\
\hline Chresta sphaerocephala DC. & 90601 & Arbustiva & $T$ & C & VU \\
\hline
\end{tabular}




\begin{tabular}{|c|c|c|c|c|c|}
\hline $\begin{array}{l}\text { Chromolaena adenolepis (Sch.Bip. ex Baker) R.M.King \& } \\
\text { H.Rob. }\end{array}$ & 23974 & Arbustiva & $\mathrm{T}$ & $\mathrm{C}$ & \\
\hline $\begin{array}{l}\text { Chromolaena congesta (Hook. \& Arn.) R.M.King \& } \\
\text { H.Rob. }\end{array}$ & 24117 & Arbustiva & $\mathrm{T}$ & Q & \\
\hline Chromolaena decumbens Gardner & 24098 & Herbácea & $\mathrm{T}$ & Q & \\
\hline Chromolaena hirsuta (Hook. \& Arn.) R.M.King \& H.Rob. & 25004 & Arbustiva & $\mathrm{T}$ & $\mathrm{C}$ & \\
\hline Chromolaena horminoides DC. & 23912 & Arbustiva & $\mathrm{T}$ & Q & \\
\hline Chromolaena laevigata (Lam.) R.M.King \& H.Rob. & 22462 & Arbustiva & $\mathrm{T}$ & $\mathrm{C}$ & \\
\hline $\begin{array}{l}\text { Chromolaena maximilianii (Schrad. ex DC.) R.M.King \& } \\
\text { H.Rob. }\end{array}$ & 90593 & Arbustiva & $\mathrm{T}$ & C - TM & \\
\hline $\begin{array}{l}\text { Chromolaena pedunculosa (Hook. \& Arn.) R.M.King \& } \\
\text { H.Rob. }\end{array}$ & 24976 & Arbustiva & $\mathrm{T}$ & Q & \\
\hline Conyza sumatrensis (Retz.) E.Walker & 24101 & Herbácea & $\mathrm{T}$ & C - AA & \\
\hline Cyrtocymura scorpioides (Lam.) H.Rob. & 24063 & Arbustiva & $\mathrm{T}$ & $\mathrm{C} / \mathrm{Q}$ & \\
\hline Dasyphyllum sprengelianum (Gardner) Cabrera & 25198 & $\begin{array}{c}\text { Arbustiva a } \\
\text { Lian. Lenh }\end{array}$ & $\mathrm{T}$ & $\begin{array}{l}\mathrm{Q}-\mathrm{TM} \\
\mathrm{C} / \mathrm{Q}\end{array}$ & \\
\hline Disynaphia ligulifolia (Hook. \& Arn.) R.M.King \& H.Rob. & 26058 & Arbustiva & $\mathrm{T}$ & Q & \\
\hline Disynaphia spathulata (Hook. \& Arn.) R.M.King \& H.Rob. & 26266 & Arbustiva & $\mathrm{T}$ & Q & \\
\hline Elaphantopus mollis Kunth & 90595 & Herbácea & $\mathrm{T}$ & $\mathrm{C}$ & \\
\hline Emilia fosbergii Nicolson & 26179 & Herbácea & $\mathrm{T}$ & $\mathrm{C}$ & \\
\hline Erechtites hieraciifolius (L.) Raf. ex DC. & 26179 & Herbácea & $\mathrm{T}$ & $\mathrm{C}$ & \\
\hline Erechtites valerianifolius (Wolf) DC. & 26384 & Herbácea & $\mathrm{T}$ & $\mathrm{C}$ & \\
\hline Eremanthus crotonoides (DC.) Sch.Bip. & 24085 & Arbustiva & $\mathrm{T}$ & Q & \\
\hline Eremanthus erythropappus (DC.) MacLeish & 24255 & Arbórea & $\mathrm{T}$ & $C / Q$ & \\
\hline Eremanthus glomerulatus Less. & 25008 & Arbórea & $\mathrm{T}$ & $\mathrm{C} / \mathrm{Q}$ & \\
\hline Gochnatia paniculata (Less.) Cabrera & 24994 & Arbustiva & $\mathrm{T}$ & $\mathrm{C} / \mathrm{Q}$ & \\
\hline Gochnatia polymorpha (Less.) Cabrera & 23908 & Arbustiva & $\mathrm{T}$ & $C / Q$ & \\
\hline Grazielia intermedia (DC.) R.M.King \& H.Rob. & 24057 & Arbustiva & $\mathrm{T}$ & Q & \\
\hline Heterocondylus amphidictyus (DC.) R.M.King \& H.Rob. & 90607 & Arbustiva & $\mathrm{T}$ & Q & \\
\hline Hololepsis pedunculata (DC. ex Pers.) DC. & 23952 & Arbustiva & $\mathrm{T}$ & $\mathrm{C}$ & \\
\hline Inulopsis camporum (Gardner) G.L.Nesom & 22106 & Arbustiva & $\mathrm{T}$ & Q & \\
\hline Inulopsis scaposa (DC.) O.Hoffm. & 94849 & Arbustiva & $\mathrm{T}$ & Q & \\
\hline Koanophyllon adamantium (Gardner) R.M.King \& H.Rob. & 94856 & Arbustiva & $\mathrm{T}$ & C - TM & \\
\hline Koanophyllon tinctorium Arruda ex H.Kost. & 23338 & Arbustiva & $\mathrm{T}$ & C & \\
\hline Leptostelma maximum D.Don & 26385 & Arbustiva & $\mathrm{T}$ & Q & \\
\hline Lessingianthus desertorum (Mart. ex DC.) H. Rob. & 22105 & Arbustiva & $\mathrm{T}$ & Q & \\
\hline Lessingianthus linearifolius (Less.) H.Rob. & 24987 & Arbustiva & $\mathrm{T}$ & $C / Q$ & \\
\hline Lessingianthus linearis (Spreng.) H.Rob. & 25003 & Arbustiva & $\mathrm{T}$ & C & \\
\hline Lepidaploa remotiflora (Rich.) H.Rob. & 94857 & Herbácea & $\mathrm{T}$ & C & \\
\hline Lepidaploa rufogrisea (A.St.-Hil.) H.Rob. & 90594 & Arbustiva & $\mathrm{T}$ & Q & \\
\hline Lucilia lycopodioides (Less.) S.E.Freire & 25005 & Arbustiva & $\mathrm{T}$ & Q & \\
\hline Lychnophora pinaster Mart. & 22012 & Arbustiva & $\mathrm{T}$ & $C / Q$ & VU \\
\hline Lychnophora syncephalla (Sch.Bip.) Sch.Bip. & 24000 & Arbustiva & $\mathrm{T}$ & $\mathrm{C} / \mathrm{Q}$ & VU \\
\hline Mikania acuminata DC. & 24991 & Lian. Lenh. & $\mathrm{T}$ & Q - TM & VU \\
\hline Mikania glauca Mart. ex Baker & 25009 & Arbustiva & $\mathrm{T}$ & $\mathrm{C} / \mathrm{Q}$ & VU \\
\hline Mikania leiolaena DC. & 24113 & Arbustiva & $\mathrm{T}$ & Q & \\
\hline Mikania lindbergii Baker & 24999 & Lian. Lenh. & $\mathrm{T}$ & C - TM & \\
\hline
\end{tabular}


A flórula rupestre do Pico de Itabirito, Minas Gerais, Brasil

\begin{tabular}{|c|c|c|c|c|c|}
\hline Mikania oblongifolia DC. & 90648 & Arbustiva & $\mathrm{T}$ & $\mathrm{C}$ & \\
\hline Mikania parvifolia (Aubl.) H.Karst. & 23924 & Lian. Lenh. & $\mathrm{T}$ & $\mathrm{Q}-\mathrm{TM}$ & VU \\
\hline Mikania phaeoclados Mart. & 25113 & Lian. Lenh. & $\mathrm{T}$ & $\mathrm{Q}-\mathrm{TM}$ & \\
\hline Mikania pilosa Baker & 24198 & Lian. Lenh. & $\mathrm{T}$ & C - TM & VU \\
\hline Mikania purpurascens (Baker) R.M.King \& H.Rob. & 26505 & Lian. Lenh. & $\mathrm{T}$ & C - TM & \\
\hline Mikania ramosissima Gardner 180 & 22177 & Lian. Lenh. & $\mathrm{T}$ & C / Q - TM & \\
\hline Piptocarpha oblonga (Gardner) Baker & 90262 & Lian. Lenh. & $\mathrm{T}$ & C - TM & \\
\hline Pluchea oblongifolia DC. & 26262 & Arbustiva & $\mathrm{T}$ & $Q-A A$ & \\
\hline Porophyllum lanceolatum DC. & 23916 & Arbustiva & $\mathrm{T}$ & Q & \\
\hline Porophyllum ruderale (Jacq.) Cass. & 90596 & Herbácea & $\mathrm{T}$ & $C-A A$ & \\
\hline Praxelis missiona (Malme) R.M.King \& H.Rob. & 23917 & Herbácea & $\mathrm{T}$ & $\mathrm{C}$ & \\
\hline Pterocaulon rugosum (Vahl) Malme & 23932 & Arbustiva & $\mathrm{T}$ & C & \\
\hline Richterago radiata (Vell.) Roque & 25123 & Herbácea & $\mathrm{T}$ & $Q$ & \\
\hline Senecio brasiliensis (Spreng.) Less. & 25300 & Herbácea & $\mathrm{T}$ & $\mathrm{C}$ & \\
\hline Senecio claussenii Decne. & 25199 & Herbácea & $\mathrm{T}$ & Q & EN \\
\hline Sonchus oleraceus L. & 90561 & Herbácea & $\mathrm{T}$ & $\mathrm{C}$ & \\
\hline Stenocephalum megapotamicum (Spreng.) Sch.Bip. & 25506 & Arbustiva & $\mathrm{T}$ & $\mathrm{C}$ & \\
\hline Stenophalium chionaeum (DC.) Anderb. & 25278 & Arbustiva & $\mathrm{T}$ & $\mathrm{C}$ & \\
\hline Stevia lundiana DC. & 90597 & Herbácea & $\mathrm{T}$ & $\mathrm{C}$ & \\
\hline Stevia urticaefolia Thunb. & 25002 & Herbácea & $\mathrm{T}$ & Q & \\
\hline Symphyopappus angustifolius Cabrera & 26352 & Arbustiva & $\mathrm{T}$ & Q & \\
\hline Tagetes minuta L. & 25135 & Herbácea & $\mathrm{T}$ & $C-A A$ & \\
\hline Trichogonia hirtiflora (DC.) Sch.Bip. ex Baker & 23942 & Herbácea & $\mathrm{T}$ & Q & \\
\hline Trichogonia salviifolia Gardner & 90598 & Herbácea & $\mathrm{T}$ & Q & \\
\hline Trichogonia villosa (Spreng.) Sch.Bip. ex Baker & 90559 & Herbácea & $\mathrm{T}$ & $C-A A$ & \\
\hline Trixis antimenorrhoea (Schrank) Kuntze & 25193 & Lian. Herb. & $\mathrm{T}$ & C - TM & \\
\hline Trixis glutinosa D.Don & 25107 & Arbustiva & $\mathrm{T}$ & Q & \\
\hline Trixis nobilis (Vell.) Katinas & 24993 & Arbustiva & $\mathrm{T}$ & C - TM & \\
\hline Trixis vauthieri DC. & 22044 & Arbustiva & $\mathrm{T}$ & $\mathrm{C}$ & \\
\hline Vernonanthura westiniana (Less.) H.Rob. & 23939 & Arbustiva & $\mathrm{T}$ & Q & \\
\hline \multicolumn{6}{|l|}{ BALANOPHORACEAE } \\
\hline Langsdorffia hypogaea Mart. & 25287 & Herbácea & $\mathrm{P}$ & $\mathrm{C}$ & \\
\hline \multicolumn{6}{|l|}{ BEGONIACEAE } \\
\hline Begonia cucullata Willd. & 26506 & Herbácea & $\mathrm{T}$ & $\mathrm{C}$ & \\
\hline Begonia hirtella Link & 26295 & Herbácea & $\mathrm{T}$ & $\mathrm{C}$ & \\
\hline Begonia rufa Thunb. & 25049 & Herbácea & $\mathrm{T}$ & $\mathrm{C}$ & \\
\hline \multicolumn{6}{|l|}{ BIGNONIACEAE } \\
\hline Anemopaegma glaucum Mart. ex DC. & 23931 & Arbustiva & $\mathrm{T}$ & $C-A A$ & \\
\hline Arrabidaea brachypoda (DC.) Bureau & 26256 & Arbustiva & $\mathrm{T}$ & Q & \\
\hline Arrabidaea patellifera (Schltdl.) Sandwith & 26186 & Lian. Lenh. & $\mathrm{T}$ & C & \\
\hline Arrabidaea sceptrum (Cham.) Sanwith & 26143 & Arbustiva & $\mathrm{T}$ & Q & \\
\hline Cybistax antisyphilitica (Mart.) Mart. & 26502 & Arbórea & $\mathrm{T}$ & $\mathrm{C}$ & \\
\hline Jacaranda caroba (Vell.) DC. & 24251 & Arbustiva & $T$ & $\mathrm{C}$ & \\
\hline Memora pedunculata (Vell.) Miers & 26167 & Arbustiva & $\mathrm{T}$ & $\mathrm{C}$ & \\
\hline Pyrostegia venusta (Ker Gawl.) Miers & 22000 & Lian. Lenh. & $\mathrm{T}$ & C - TM & \\
\hline
\end{tabular}




\begin{tabular}{|c|c|c|c|c|c|}
\hline Handroanthus ochraceus (Cham.) Mattos & 32036 & Arbórea & $\mathrm{T}$ & $\mathrm{C}$ & \\
\hline Zeyheria montana Mart. & 26527 & Arbustiva & $\mathrm{T}$ & Q & \\
\hline \multicolumn{6}{|l|}{ BROMELIACEAE } \\
\hline Aechmea bromeliifolia (Rudge) Baker & 24107 & Herbácea & $E$ & C - TM & \\
\hline Aechmea nudicaulis (L.) Griseb. & 25104 & Herbácea & $\mathrm{E}$ & Q - TM & \\
\hline Ananas ananassoides (Baker) L.B.Sm. & 26188 & Herbácea & $\mathrm{T}$ & $\mathrm{C}$ & \\
\hline Bilbergia amoena (Lodd.) Lindl. & 24109 & Herbácea & $S$ & $C / Q$ & \\
\hline Cryptanthus schwackeanus Mez & 26161 & Herbácea & $S / T$ & Q & VU \\
\hline Dyckia macedoi L.B.Sm. & 25141 & Herbácea & $\mathrm{S} / \mathrm{T}$ & Q & EN \\
\hline Dyckia rariflora Mart. ex Schult. \& Schult.f. & 26146 & Herbácea & $\mathrm{S} / \mathrm{T}$ & Q & CR \\
\hline Tillandsia gardneri Lindl. & 25197 & Herbácea & $\mathrm{R} / \mathrm{E}$ & & \\
\hline Tillandsia stricta Sol & 22342 & Herbácea & $\mathrm{R} / \mathrm{E}$ & $C / Q$ & \\
\hline Vriesea crassa Mez & 24111 & Herbácea & $\mathrm{S}$ & $\mathrm{C}$ & \\
\hline \multicolumn{6}{|l|}{ BURMANNIACEAE } \\
\hline Burmannia bicolor Mart. & 25120 & Herbácea & $\mathrm{T}$ & $\mathrm{C}$ & \\
\hline \multicolumn{6}{|l|}{ BURSERACEAE } \\
\hline Protium brasiliense (Spreng.) Engl. & 26300 & Arvoreta & $\mathrm{T}$ & Q & \\
\hline \multicolumn{6}{|l|}{ CACTACEAE } \\
\hline Arthrocereus glaziovii (K.Schum.) N.P.Taylor \& Zappi & 24108 & Herbácea & $\mathrm{S} / \mathrm{R}$ & $\mathrm{C}$ & CR \\
\hline Cipocereus minensis (Werderm.) Ritter & 24250 & Herbácea & $S / R$ & Q & \\
\hline Hatiora salicornioides (Haw.) Britton \& Rose & 25050 & Herbácea & $\mathrm{S} / \mathrm{R} / \mathrm{E}$ & $\mathrm{C}$ & \\
\hline Rhipsalis floccosa Salm-Dyck ex Pfeiff. & 26517 & Herbácea & $\mathrm{S} / \mathrm{R} / \mathrm{E}$ & $\mathrm{C}$ & \\
\hline \multicolumn{6}{|l|}{ CAMPANULACEAE } \\
\hline Lobelia camporum Pohl & 26531 & Herbácea & $\mathrm{T}$ & Q & \\
\hline Siphocampylus corymbiferus Pohl & 90591 & Herbácea & $\mathrm{T}$ & C & \\
\hline Siphocampylus nitidus Pohl & 22091 & Arbustiva & $\mathrm{T}$ & Q & \\
\hline Siphocampylus imbricatus (Cham.) G.Don & 22340 & Arbustiva & $\mathrm{T}$ & C & \\
\hline Wahlenbergia brasiliensis Cham. & 26133 & Arbustiva & $\mathrm{T}$ & Q & \\
\hline \multicolumn{6}{|l|}{ CELASTRACEAE } \\
\hline Maytenus gonoclada Mart. & 31019 & Arbustiva & $\mathrm{T}$ & $\mathrm{C}$ & \\
\hline \multicolumn{6}{|l|}{ CLEOMACEAE } \\
\hline Cleome rosea Vahl ex DC. & 24069 & Herbácea & $\mathrm{T}$ & C - TM & \\
\hline \multicolumn{6}{|l|}{ CLETHRACEAE } \\
\hline Clethra scabra Pers. & 25063 & Abórea & $\mathrm{T}$ & C / Q - TM & \\
\hline \multicolumn{6}{|l|}{ CLUSIACEAE } \\
\hline Arrudea clusioides Cambess. & 28502 & Arbórea & $\mathrm{T}$ & $\mathrm{C}$ & \\
\hline Kielmeyera pumila Pohl & 23352 & Arbustiva & $\mathrm{T}$ & Q & \\
\hline Kielmeyera variabilis Mart. \& Zucc. & 26261 & Arbustiva & $\mathrm{T}$ & Q & \\
\hline \multicolumn{6}{|l|}{ COMMELINACEAE } \\
\hline Commelina obliqua Vahl & 23339 & Herbácea & $\mathrm{T}$ & $\mathrm{C}$ & \\
\hline Dichorisandra hexandra (Aubl.) Kuntze ex Hand.-Mazz. & 23990 & Herbácea & $\mathrm{T}$ & C - TM & \\
\hline \multicolumn{6}{|l|}{ CONVOLVULACEAE } \\
\hline Evolvulus filipes Mart. & 26381 & Lian. Herb. & $\mathrm{T}$ & C & \\
\hline Ipomoea cf. aristolochiifolia G.Don & 94848 & Lian. Herb. & $\mathrm{T}$ & $\mathrm{C}$ & \\
\hline Ipomoea delphinioides Choisy & 23272 & Lian. Herb. & $\mathrm{T}$ & Q & \\
\hline
\end{tabular}


A flórula rupestre do Pico de Itabirito, Minas Gerais, Brasil

\begin{tabular}{|c|c|c|c|c|c|}
\hline Ipomoea procumbens Mart. ex Choisy & 26183 & Lian. Herb. & $\mathrm{T}$ & C - TM & \\
\hline Jacquemontia lasioclados (Choisy) O'Donell & 24062 & Herbácea & $\mathrm{T}$ & Q & \\
\hline Jacquemontia linarioides Meisn. & 24089 & Lian. Herb. & $\mathrm{T}$ & $\mathrm{C}$ & \\
\hline Merremia flagellaris (Choisy) O'Donell & 25112 & Lian. Herb. & $\mathrm{T}$ & Q & \\
\hline Merremia repens D.F.Austin & 25056 & Lian. Herb. & $\mathrm{T}$ & Q & VU \\
\hline \multicolumn{6}{|l|}{ CUNONIACEAE } \\
\hline Lamanonia ternata Vell. & 33813 & Arbórea & $\mathrm{T}$ & $\mathrm{C}$ & \\
\hline \multicolumn{6}{|l|}{ CYPERACEAE } \\
\hline Bulbostylis junciformis (Kunth) C.B.Clarke & 22046 & Herbácea & $\mathrm{T}$ & $\mathrm{C}$ & \\
\hline Bulbostylis paradoxa (Spreng.) Lindm. & 26267 & Herbácea & $\mathrm{T}$ & Q & \\
\hline Cyperus aggregatus (Willd. Endl. & 24261 & Herbácea & $\mathrm{T}$ & Q & \\
\hline Cyperus haspan L. & 24090 & Herbácea & $\mathrm{T}$ & $\mathrm{C}$ & \\
\hline Eleocharis capillacea Kunth & 26049 & Herbácea & $\mathrm{T}$ & $\mathrm{C}$ & \\
\hline Fimbristylis complanata (Retz.) Link & 25078 & Herbácea & $\mathrm{T}$ & Q & \\
\hline Lagenocarpus rigidus Nees & 22107 & Herbácea & $\mathrm{T}$ & $\mathrm{C}$ & \\
\hline Rhynchospora consanguinea (Kunth) Boeckeler & 23290 & Herbácea & $\mathrm{T}$ & $\mathrm{C}$ & \\
\hline Rhynchospora exaltata Kunth & 25070 & Herbácea & $\mathrm{T}$ & $\mathrm{C}$ & \\
\hline Rhynchospora globosa (Kunth) Roem. \& Schult. & 24073 & Herbácea & $\mathrm{T}$ & Q & \\
\hline Rhynchospora rugosa (Vahl) Gale & 23961 & Herbácea & $\mathrm{T}$ & Q & \\
\hline Rhynchospora setigera (Kunth) Boeckeler & 25072 & Herbácea & $\mathrm{T}$ & Q & \\
\hline Scleria cf. atroglumis D.A.Simpson & 23953 & Herbácea & $\mathrm{T}$ & $\mathrm{C}$ & \\
\hline Scleria hirtella Sw. & 26376 & Herbácea & $\mathrm{T}$ & Q & \\
\hline Trilepis Ihotzkiana Nees ex Arn. & 25076 & Herbácea & $\mathrm{T}$ & $\mathrm{C}$ & \\
\hline \multicolumn{6}{|l|}{ DIOSCOREACEAE } \\
\hline Dioscorea debilis Uline ex R.Knuth & 25266 & Lian. Herb. & $\mathrm{T}$ & $C / Q$ & \\
\hline \multicolumn{6}{|l|}{ DROSERACEAE } \\
\hline Drosera montana A.St.-Hil. & 23968 & Herbácea & $\mathrm{S} / \mathrm{R} / \mathrm{T}$ & $C / Q$ & \\
\hline \multicolumn{6}{|l|}{ ERICACEAE } \\
\hline Agarista eucalyptoides (Cham. \& Schltdl.) G.Don & 29787 & Arvoreta & $\mathrm{T}$ & $\mathrm{C}$ & \\
\hline Agarista oleifolia var. glabra (Meisn.) Judd & 25188 & Arbustiva & $\mathrm{T}$ & $C / Q$ & \\
\hline Agarista oleifolia (Cham.) G.Don var. oleifolia & 26053 & Arbustiva & $\mathrm{T}$ & $\mathrm{C} / \mathrm{Q}$ & \\
\hline Agarista pulchra (Cham. \& Schltdl.) G.Don & 26281 & Arbustiva & $\mathrm{T}$ & $\mathrm{C}$ & \\
\hline Gaylussacia decipiens Cham. & 24252 & Arbutiva. & $\mathrm{T}$ & Q & \\
\hline Gaylussacia pseudogaultheria Cham. \& Schltdl. & 25302 & Arbustiva & $T$ & Q & \\
\hline Gaylussacia reticulata var. salviifolia Sleumer & 25272 & Arbustiva & $\mathrm{T}$ & Q & \\
\hline \multicolumn{6}{|l|}{ ERIOCAULACEAE } \\
\hline Actinocephalus bongardii (A.St.-Hil.) Sano & 24195 & Herbácea & $\mathrm{T}$ & Q & \\
\hline Comanthera vernonioides (Kunth) L.R.Parra \& Giul. & 25111 & Herbácea & $\mathrm{T}$ & Q & EN \\
\hline Eriocaulon ligulatum (Vell.) L.B.Sm. & 26050 & Herbácea & $\mathrm{T}$ & C & \\
\hline Paepalanthus clausseni Hensold & 24258 & Herbácea & $\mathrm{T}$ & Q & \\
\hline Paepalanthus elongatus (Bong.) Körn. & 22076 & Herbácea & $\mathrm{T}$ & Q & \\
\hline Paepalanthus flaccidus (Bong.) Kunth & 26500 & Herbácea & $\mathrm{T}$ & & \\
\hline Paepalanthus manicatus Poulsen ex Malme & 23933 & Herbácea & $\mathrm{T}$ & $\mathrm{C}$ & \\
\hline Paepalanthus pubescens Körn. & 25137 & Herbácea & $\mathrm{T}$ & Q & \\
\hline Paepalanthus chiquitensis Herzog & 26523 & Herbácea & $\mathrm{T}$ & Q & \\
\hline
\end{tabular}




\begin{tabular}{|c|c|c|c|c|c|}
\hline Paepalanthus tortilis (Bong.) Mart. & 24051 & Herbácea & $\mathrm{T}$ & $C / Q$ & \\
\hline Philodice hoffmannseggii Mart. & 28504 & Herbácea & $\mathrm{T}$ & Q & \\
\hline Syngonanthus anthemidiflorus (Bong.) Ruhland & 26263 & Herbácea & $\mathrm{T}$ & Q & \\
\hline Syngonanthus fischerianus (Bong.) Ruhland & 26163 & Herbácea & $\mathrm{T}$ & Q & \\
\hline Syngonanthus gracilis (Bong.) Ruhland & 28505 & Herbácea & $\mathrm{T}$ & Q & \\
\hline \multicolumn{6}{|l|}{ ERYTHROXYLACEAE } \\
\hline Erythroxylum campestre A.St.-Hil. & 25046 & Arbustiva & $\mathrm{T}$ & $\mathrm{C}$ & \\
\hline Erythroxylum suberosum A.St.-Hil. & 26038 & Arbustiva & $\mathrm{T}$ & Q & \\
\hline Erythroxylum tortuosum Mart. & 25312 & Arbustiva & $\mathrm{T}$ & Q & \\
\hline \multicolumn{6}{|l|}{ EUPHORBIACEAE } \\
\hline Euphorbia potentilloides Boiss. & 25096 & Herbácea & $\mathrm{T}$ & C & \\
\hline Croton atrorufus Müll.Arg. & 3178 & Herbácea & $\mathrm{T}$ & C & \\
\hline Croton burchellii Müll.Arg. & 25086 & Arbustiva & $\mathrm{T}$ & $\mathrm{C}$ & \\
\hline Croton campestris A.St.-Hil. & 23970 & Arbustiva & $\mathrm{T}$ & $\mathrm{C}$ & \\
\hline Croton echinocarpus Müll.Arg. & 23944 & Arbórea & $\mathrm{T}$ & C - TM & \\
\hline Croton timandroides (Didr.) Müll.Arg. & 31032 & Herbácea & $\mathrm{T}$ & $\mathrm{C}$ & \\
\hline Euphorbia potentilloides Boiss. & 25096 & Herbácea & $\mathrm{T}$ & $\mathrm{C}$ & \\
\hline Microstachys daphnoides (Mart.) Müll.Arg. & 23915 & Arbustiva & $\mathrm{T}$ & Q & \\
\hline Sapium glandulosum (L.) Morong & 26369 & Arbustiva & $\mathrm{T}$ & $\mathrm{C}$ & \\
\hline \multicolumn{6}{|l|}{ FABACEAE } \\
\hline Aeschynomene falcata (Poir.) DC. & 26363 & Arbustiva & $\mathrm{T}$ & $\mathrm{C}$ & \\
\hline Bauhinia rufa (Bong.) Steud. & 24002 & Arvoreta & $\mathrm{T}$ & $\mathrm{C}$ & \\
\hline Bowdichia virgilioides Kunth & 26046 & Arbórea & $\mathrm{T}$ & Q & \\
\hline Camptosema scarlatinum (Mart. ex Benth.) Burkart & 26044 & Lian. Herb. & $\mathrm{T}$ & Q & \\
\hline Centrosema arenarium Benth. & 23911 & Lian. Herb. & $\mathrm{T}$ & $\mathrm{C}$ & \\
\hline Chamaecrista cathartica (Mart.) H.S.Irwin \& Barneby & 25033 & Arbustiva & $\mathrm{T}$ & $\mathrm{C}$ & \\
\hline Chamaecrista ciliolata (Benth.) H.S.Irwin \& Barneby & 25032 & Arbustiva & $\mathrm{T}$ & C - AA & \\
\hline Chamaecrista desvauxii (Collad.) Killip & 26357 & Arbustiva & $\mathrm{T}$ & Q & \\
\hline Chamaecrista diphylla (L.) Greene & 32038 & Arbustiva & $\mathrm{T}$ & Q & \\
\hline Chamaecrista nictitans (L.) Moench & 26187 & Arbustiva & $\mathrm{T}$ & $\mathrm{C}$ & \\
\hline Chamaecrista ochnacea (Vogel) H.S.Irwin \& Barneby & 25036 & Arbustiva & $\mathrm{T}$ & Q & \\
\hline Chamaecrista ramosa (Vogel) H.S.Irwin \& Barneby & 23936 & Arbustiva & $\mathrm{T}$ & $\mathrm{C}$ & \\
\hline Chamaecrista secunda (Benth.) H.S.Irwin \& Barneby & 23945 & Arbustiva & $\mathrm{T}$ & $\mathrm{C}$ & \\
\hline Collaea macrophylla Benth. & 25299 & Arbustiva & $\mathrm{T}$ & $\mathrm{C}$ & \\
\hline Copaifera langsdorffii Desf. & 25035 & Arbórea & $\mathrm{T}$ & $C / Q$ & \\
\hline Crotalaria unifoliolata Benth. & 26151 & Arbustiva & $\mathrm{T}$ & $\mathrm{C}$ & \\
\hline Dalbergia miscolobium Benth. & 24460 & Arbórea & $\mathrm{T}$ & C - TM & \\
\hline Dalbergia villosa (Benth.) Benth. & 23958 & Arbórea & $\mathrm{T}$ & C - TM & \\
\hline Eriosema heterophyllum Benth. & 25296 & Arbustiva & $\mathrm{T}$ & $\mathrm{C}$ & \\
\hline Galactia martii DC. & 26292 & Arbustiva & $\mathrm{T}$ & $\mathrm{C}$ & \\
\hline Inga vulpina Mart. ex Benth. & 25040 & Arbórea & $\mathrm{T}$ & C - TM & VU \\
\hline Lupinus velutinus Benth. & 90605 & Arbustiva & $\mathrm{T}$ & $\mathrm{C}$ & \\
\hline Macrosamanea pedicellaris (DC.) Kleinh. & 23947 & Arbórea & $\mathrm{T}$ & $\mathrm{Q}-\mathrm{TM}$ & \\
\hline Mimosa calodendron Mart. ex Benth. & 24097 & Arbustiva & $\mathrm{T}$ & $\mathrm{C}$ & \\
\hline
\end{tabular}


A flórula rupestre do Pico de Itabirito, Minas Gerais, Brasil

\begin{tabular}{|c|c|c|c|c|c|}
\hline Mimosa setosa var. paludosa (Benth.) Barneby & 25034 & Arbustiva & $\mathrm{T}$ & $Q-A A$ & \\
\hline Mimosa setistipula Benth. & 25038 & Arbustiva & $\mathrm{T}$ & $\mathrm{C}$ & \\
\hline Macroptilium atropurpureum (Sessé \& Moc. ex DC.) Urb. & 23919 & Lian. Herb. & $\mathrm{T}$ & $C-A A$ & \\
\hline Periandra mediterranea (Vell.) Taub. & 25271 & Arbustiva & $\mathrm{T}$ & $C / Q$ & \\
\hline Piptadenia adiantoides (Spreng.) J.F.Macbr. & 24263 & Lian. Lenh. & $\mathrm{T}$ & C - TM & \\
\hline Sclerolobium rugosum Mart. & 90650 & Arbórea & $T$ & C - TM & \\
\hline Senna macranthera (DC. ex collad.) H.S.Irwin \& Barneby & 26155 & Arbórea & $\mathrm{T}$ & $\mathrm{C}$ & \\
\hline $\begin{array}{l}\text { Senna pendula (Humb. \& Bonpl. ex Willd.) H.S.Irwin \& } \\
\text { Barneby }\end{array}$ & 24262 & Arbustiva & $\mathrm{T}$ & $\mathrm{C}$ & \\
\hline Senna reniformis (G. Don) H.S.Irwin \& Barneby & 25048 & Arbustiva & $\mathrm{T}$ & $\mathrm{C}$ & \\
\hline Senna rugosa (G. Don) H.S.Irwin \& Barneby & 24059 & Arbustiva & $\mathrm{T}$ & Q & \\
\hline Stylosanthes gracilis Kunth & 23998 & Arbustiva & $\mathrm{T}$ & $\mathrm{C}$ & \\
\hline Stylosanthes viscosa (L.) Sw. & 28494 & Arbustiva & $\mathrm{T}$ & Q & \\
\hline \multicolumn{6}{|l|}{ GENTIANACEAE } \\
\hline Calolisianthus pedunculatus (Cham. \& Schltdl.) Gilg & 23938 & Herbácea & $\mathrm{T}$ & C / Q - TM & \\
\hline Calolisianthus speciosus (Cham. \& Schldt.) Gilg & 90574 & Herbácea & $\mathrm{T}$ & Q & \\
\hline Curtia tenuifolia (Aubl.) Knobl. & 28500 & Herbácea & $\mathrm{T}$ & $\mathrm{C}$ & \\
\hline Curtia tenuifolia (Aubl.) Knobl & 90575 & Herbácea & $\mathrm{T}$ & Q & \\
\hline Curtia diffusa (Mart.) Cham. & 90576 & Herbácea & $\mathrm{T}$ & Q & \\
\hline Deianira nervosa Cham. \& Schltdl. & 23977 & Herbácea & $\mathrm{T}$ & Q & \\
\hline Schultesia gracilis Mart. & 25140 & Herbácea & $\mathrm{T}$ & Q & \\
\hline \multicolumn{6}{|l|}{ GESNERIACEAE } \\
\hline Nematanthus strigillosus (Mart.) H.E.Moore & 23349 & Herbácea & $\mathrm{S} / \mathrm{R}$ & Q & \\
\hline Paliavana sericiflora Benth. & 23965 & Arbustiva & $\mathrm{S} / \mathrm{R}$ & $\mathrm{C} / \mathrm{Q}$ & VU \\
\hline Sinningia aggregata (Ker Gawler) Wiehler & 23960 & Arbustiva & $\mathrm{S} / \mathrm{R}$ & $\mathrm{C}$ & \\
\hline Sinningia allagophylla (Mart.) Wiehler & 24110 & Arbustiva & $\mathrm{T}$ & Q & \\
\hline Sinningia magnifica (Otto \& A. Dietr.) Wiehler & 23935 & Arbustiva & $\mathrm{S} / \mathrm{R}$ & $C / Q$ & \\
\hline Sinningia rupicola (Mart.) Wiehler & 26180 & Arbustiva & $\mathrm{S} / \mathrm{R}$ & C & VU \\
\hline \multicolumn{6}{|l|}{ HYPERICACEAE } \\
\hline Vismia brasiliensis Choisy & 28451 & Arbórea & $\mathrm{T}$ & Q & \\
\hline Vismia micrantha A.St.-Hil & 26311 & Arbórea & $\mathrm{T}$ & $\mathrm{C}$ & \\
\hline Vismia parviflora Cham. \& Schltdl. & 26140 & Arbórea & $\mathrm{T}$ & Q & \\
\hline \multicolumn{6}{|l|}{ IRIDACEAE } \\
\hline Cipura paludosa Aubl. & 26277 & Herbácea & $\mathrm{T}$ & Q & \\
\hline Neomarica rupestris (Ravenna) Chukr & 26291 & Herbácea & $\mathrm{T}$ & $\mathrm{C}$ & VU \\
\hline Sisyrinchium vaginatum Spreng. & 26532 & Herbácea & $\mathrm{T}$ & Q & \\
\hline Trimezia juncifolia (Klatt) Benth. \& Hook. & 24102 & Herbácea & $\mathrm{T}$ & Q & \\
\hline Trimezia lutea (Klatt) Foster & 26366 & Herbácea & $\mathrm{T}$ & Q & \\
\hline \multicolumn{6}{|l|}{ JUNCACEAE } \\
\hline Juncus microcephalus Kunth & 26358 & Herbácea & $A$ & Q & \\
\hline \multicolumn{6}{|l|}{ LAMIACEAE } \\
\hline Aegiphila verticillata Vell. & 25255 & Arvoreta & $\mathrm{T}$ & $\mathrm{C}$ & \\
\hline Eriope macrostachya Mart. ex Benth. & 25268 & Arbustiva & $\mathrm{T}$ & C & \\
\hline Hyptis crinita Benth. & 25276 & Arbustiva & $\mathrm{T}$ & $\mathrm{C}$ & \\
\hline Hyptis lippioides Pohl ex Benth. & 25252 & Arbustiva & $\mathrm{T}$ & $Q$ & \\
\hline
\end{tabular}




\begin{tabular}{|c|c|c|c|c|c|}
\hline Hyptis marrubioides Epling & 28551 & Herbácea & $\mathrm{T}$ & $Q$ & \\
\hline Hyptis mutabilis (Rich.) Briq. & 90552 & Herbácea & $T$ & C - AA & \\
\hline Hyptis nudicaulis Benth. & 25189 & Arbustiva & $\mathrm{T}$ & $\mathrm{C}$ & \\
\hline Hyptis plectranthoides Benth. & 26299 & Herbácea & $\mathrm{T}$ & $\mathrm{C}$ & \\
\hline Hyptis rotundifolia Benth. & 25131 & Arbustiva & $\mathrm{T}$ & $C / Q$ & \\
\hline Hyptis rubiginosa Benth. & 25202 & Arbustiva & $\mathrm{T}$ & Q & \\
\hline Vitex megapotamica (Spreng.) Moldenke & 25284 & Arbustiva & $\mathrm{T}$ & $C / Q$ & \\
\hline Vitex polygama Cham. & 22339 & Arbusto & $\mathrm{T}$ & C - TM & \\
\hline \multicolumn{6}{|l|}{ LAURACEAE } \\
\hline Cassytha filiformis (L.) & 90554 & Lian. Herb. & $\mathrm{P}$ & Q & \\
\hline Cinnamomum oleifolium (Mez.) Kosterm. & 25059 & Arbustiva & $\mathrm{T}$ & Q & \\
\hline Cinnamomum quadrangulum Kosterm. & 26169 & Arbustiva & $\mathrm{T}$ & C & EN \\
\hline Ocotea cf. complicata (Meisn.) Mez & 26025 & Arbórea & $T$ & $Q-T M$ & \\
\hline Ocotea percoriacea Kosterm. & 26136 & Arvoreta & $\mathrm{T}$ & $C / Q$ & \\
\hline Ocotea pomaderroides (Meisn.) Mez & 26067 & Arbórea & $\mathrm{T}$ & Q & \\
\hline Ocotea spixiana (Ness) Mez & 23928 & Arbórea & $\mathrm{T}$ & $\mathrm{C}$ & \\
\hline Ocotea tristis (Ness \& Mart.) Mez & 25117 & Arbustiva & $\mathrm{T}$ & $\mathrm{C}$ & \\
\hline \multicolumn{6}{|l|}{ LENTIBULARIACEAE } \\
\hline Genlisea repens Benj. & 23927 & Herbácea & $\mathrm{T}$ & $\mathrm{C}$ & \\
\hline Utricularia nervosa G. Weber ex Benj. & 23927 & Herbácea & $A$ & $\mathrm{C}$ & \\
\hline \multicolumn{6}{|l|}{ LOGANIACEAE } \\
\hline Spigelia blanchetiana A.DC. & 26361 & Herbácea & $\mathrm{T}$ & $Q$ & \\
\hline Spigelia olfersiana Cham. \& Schltdl. & 26251 & Herbácea & $\mathrm{T}$ & Q & \\
\hline Spigelia schlechtendaliana Mart. & 25144 & Herbácea & $\mathrm{T}$ & $\mathrm{C}$ & \\
\hline Spigelia sellowiana Cham. \& Schltdl. & 26064 & Herbácea & $\mathrm{T}$ & $Q$ & VU \\
\hline \multicolumn{6}{|l|}{ LORANTHACEAE } \\
\hline Struthanthus flexicaulis Mart. & 26288 & Lenhosa & $\mathrm{H}$ & $\mathrm{C}$ & \\
\hline Struthanthus marginatus (Desr.) Blume & 25127 & Lenhosa & $\mathrm{H}$ & $\mathrm{C}$ & \\
\hline \multicolumn{6}{|l|}{ LYTHRACEAE } \\
\hline Cuphea thymoides Cham. \& Schltdl. & 26051 & Herbácea & $\mathrm{T}$ & $\mathrm{C}$ & \\
\hline Diplusodon buxifolius (Cham. \& Schltdl.) A.DC. & 25022 & Arbustiva & $\mathrm{T}$ & Q & \\
\hline Diplusodon hirsutus (Cham. \& Schltdl.) A.DC. & 25023 & Arbustiva & $\mathrm{T}$ & $\mathrm{C}$ & \\
\hline Diplusodon virgatus Pohl & 26302 & Arbustiva & $\mathrm{T}$ & Q & \\
\hline Lafoensia pacari A.St.-Hil. & 25030 & Arbórea & $\mathrm{T}$ & Q & \\
\hline \multicolumn{6}{|l|}{ MALPIGHIACEAE } \\
\hline Banisteriopsis angustifolia (A.Juss.) B. Gates & 24088 & Arbustiva & $\mathrm{T}$ & $Q$ & \\
\hline Banisteriopsis anisandra (A.Juss.) B.Gates & 25289 & Lian. Lenh. & $\mathrm{T}$ & Q - TM & \\
\hline Banisteriopsis campestris (A .Juss.) Little & 24007 & Arbustiva & $\mathrm{T}$ & Q & \\
\hline Banisteriopsis malifolia (Ness \& Mart.) B.Gates & 23918 & Arbustiva & $\mathrm{T}$ & $\mathrm{C} / \mathrm{Q}$ & \\
\hline $\begin{array}{l}\text { Diplopterys pubipetala (A.Juss.) W.R.Anderson \& } \\
\text { C.C.Davis }\end{array}$ & 25298 & Lian. Lenh. & $\mathrm{T}$ & C - TM & \\
\hline Byrsonima clausseniana A.Juss. & 25041 & Arbustiva & $\mathrm{T}$ & Q & \\
\hline Byrsonima pachyphylla A.Juss. & 25042 & Arbustiva & $\mathrm{T}$ & Q & \\
\hline Byrsonima intermedia A.Juss. & 24086 & Arbustiva & $\mathrm{T}$ & $Q$ & \\
\hline Byrsonima variabilis A.Juss. & 25285 & Arbustiva & $\mathrm{T}$ & $Q$ & \\
\hline
\end{tabular}


A flórula rupestre do Pico de Itabirito, Minas Gerais, Brasil

\begin{tabular}{|c|c|c|c|c|c|}
\hline Byrsonima verbascifolia (L.) DC. & 24096 & Arbustiva & $\mathrm{T}$ & Q & \\
\hline Camarea affinis A.St.-Hil. & 26165 & Herbácea & $\mathrm{T}$ & Q & \\
\hline Camarea hirsuta A.St.-Hil. & 23967 & Herbácea & $\mathrm{T}$ & $\mathrm{C}$ & VU \\
\hline Heteropterys campestris A.Juss. & 26511 & Arbustiva & $\mathrm{T}$ & $\mathrm{C}$ & \\
\hline Heteropterys escalloniifolia A.Juss. & 26061 & Arbórea & $\mathrm{T}$ & $Q-T M$ & \\
\hline Heteropterys umbellata A.Juss. & 26042 & Arbustiva & $\mathrm{T}$ & $Q$ & \\
\hline Peixotoa tomentosa A.Juss. & 23950 & Arbustiva & $\mathrm{T}$ & $\mathrm{C}$ & \\
\hline Pterandra pyroidea A.Juss. & 26040 & Arbustiva & $\mathrm{T}$ & Q & \\
\hline Tetrapterys microphylla (A.Juss.) Nied. & 22178 & Arbustiva & $\mathrm{T}$ & C / Q - TM & \\
\hline \multicolumn{6}{|l|}{ MALVACEAE } \\
\hline Abutilon rufinerve A.St.-Hil. & 90600 & Arbustiva & $\mathrm{T}$ & $Q-T M$ & \\
\hline Krapovickasia macrodon (A.DC.) Fryxell & 28550 & Arbustiva & $\mathrm{T}$ & Q & \\
\hline Pavonia schwackei Gürke & 24199 & Arbustiva & $\mathrm{T}$ & $\mathrm{C}$ & \\
\hline Peltaea parviflora (Tuncz.) Fryxell \& Krapov. & 23962 & Herbácea & $\mathrm{T}$ & Q & \\
\hline Peltaea polymorpha (A.St. -Hil.) Krapov. \& Cristóbal & 23956 & Arbustiva & $\mathrm{T}$ & $\mathrm{C}$ & \\
\hline Sida glaziovii K.Schum. & 26062 & Herbácea & $\mathrm{T}$ & Q & \\
\hline Sida linifolia Cav. & 23940 & Herbácea & $\mathrm{T}$ & $\mathrm{C}$ & \\
\hline Sida martiana A.St.-Hil. & 23907 & Herbácea & $\mathrm{T}$ & Q & \\
\hline Triumfetta semitriloba Jacq. & 90606 & Arbustiva & $\mathrm{T}$ & C - TM & \\
\hline Waltheria communis A.St.-Hil & 26059 & Arbustiva & $\mathrm{T}$ & $\mathrm{C}$ & \\
\hline Waltheria americana $\mathrm{L}$. & 26286 & Arbustiva & $\mathrm{T}$ & $\mathrm{C}$ & \\
\hline \multicolumn{6}{|l|}{ MELASTOMATACEAE } \\
\hline Acisanthera quadrata Pers. & 23921 & Herbácea & $\mathrm{T}$ & Q & \\
\hline Cambessedesia corymbosa Mart. \& Schrank ex DC. & 23996 & Herbácea & $\mathrm{T}$ & $C / Q$ & \\
\hline Cambessedesia espora (A.St.-Hil. ex Bonpl.) DC. & 24071 & Arbustiva & $\mathrm{T}$ & $C / Q$ & \\
\hline Cambessedesia hilariana (Kunth) DC. & 24075 & Herbácea & $\mathrm{T}$ & Q & \\
\hline Chaetostoma armatum (Spreng.) Cogn. & 26182 & Herbácea & $\mathrm{T}$ & C - AA & \\
\hline Comolia sertularia (DC.)Triana & 22010 & Herbácea & $\mathrm{T}$ & Q & \\
\hline Comolia sessilis (Spreng.) Triana & 21766 & Herbácea & $\mathrm{T}$ & Q & \\
\hline Lavoisiera alba Mart. \& Schrank ex DC. & 23994 & Arbustiva & $\mathrm{T}$ & Q & \\
\hline Lavoisiera imbricata (Thunb.) DC. & 25024 & Arbustiva & $\mathrm{T}$ & Q & \\
\hline Leandra aurea (Cham.) Cogn. & 26033 & Arbustiva & $\mathrm{T}$ & Q & \\
\hline Leandra australis (Cham.) Cogn. & 22248 & Arbustiva & $\mathrm{T}$ & $C / Q$ & \\
\hline Leandra erostrata (DC.) Cogn. & 26159 & Arbustiva & $\mathrm{T}$ & C & \\
\hline Leandra lacunosa Cogn. & 22094 & Arbustiva & $\mathrm{T}$ & $C / Q$ & \\
\hline Leandra melastomoides Raddi & 24001 & Arbustiva & $\mathrm{T}$ & $\mathrm{C}$ & \\
\hline Marcetia taxifolia (A.St.-Hil.) DC. & 24070 & Arbustiva & $\mathrm{T}$ & Q & \\
\hline Miconia albicans (Sw.) Triana & 26147 & Arbustiva & $\mathrm{T}$ & $C / Q$ & \\
\hline Miconia chartacea Triana & 25025 & Arbustiva & $\mathrm{T}$ & C - TM & \\
\hline Miconia cubatanensis Hoehne & 23937 & Arbustiva & $\mathrm{T}$ & $\mathrm{C}$ & \\
\hline Miconia ligustroides (DC.) Naudin & 26056 & Arbustiva & $\mathrm{T}$ & Q & \\
\hline Miconia macrothyrsa Benth. & 26034 & Arbustiva & $\mathrm{T}$ & Q & \\
\hline Miconia pepericarpa DC. & 26164 & Arbustiva & $\mathrm{T}$ & $\mathrm{C}$ & \\
\hline Miconia prasina (Sw.) DC. & 23963 & Arbustiva & $\mathrm{T}$ & Q & \\
\hline Miconia sellowiana Naudin & 22092 & Arbustiva & $\mathrm{T}$ & C - TM & \\
\hline
\end{tabular}




\begin{tabular}{|c|c|c|c|c|}
\hline Miconia theizans (Bonpl.) Cogn. & 26378 & Avoreta & $\mathrm{T}$ & C - TM \\
\hline Microlepis oleaefolia (DC.) Triana & 26524 & Arbustiva & $\mathrm{T}$ & C \\
\hline Microlicia cardiophora Naudin & 21781 & Arbustiva & $\mathrm{T}$ & $Q$ \\
\hline Microlicia cordata (Spreng.) Naudin & 25026 & Arbustiva & $\mathrm{T}$ & Q \\
\hline Microlicia crenulata (DC.) Mart. & 24056 & Arbustiva & $\mathrm{T}$ & Q \\
\hline Microlicia euphorbioides Mart. & 25020 & Arbustiva & $\mathrm{T}$ & $\mathrm{C}$ \\
\hline Microlicia fasciculata Mart. ex Naudin & 24253 & Arbustiva & $\mathrm{T}$ & Q \\
\hline Microlicia glandulifera Cogn. & 16441 & Arbustiva & $\mathrm{T}$ & Q \\
\hline Microlicia isophylla DC. & 26264 & Arbustiva & $\mathrm{T}$ & Q \\
\hline Ossaea cinnamomifolia (Naudin) Triana & 25295 & Arbustiva & $\mathrm{T}$ & $Q$ \\
\hline Ossaea coriacea (Naudin) Triana & 24100 & Arbustiva & $\mathrm{T}$ & Q \\
\hline Pterolepis repanda (DC.) Triana & 94871 & Herbácea & $\mathrm{T}$ & Q \\
\hline Rhynchanthera grandiflora (Aubl.) DC. & 23993 & Herbácea & $\mathrm{T}$ & Q \\
\hline Siphanthera cordata Pohl ex DC. & 25027 & Herbácea & $\mathrm{T}$ & $\mathrm{C}$ \\
\hline Tibouchina canescens (D.Don) Cogn. & 24205 & Arbórea & $T$ & $Q-T M$ \\
\hline Tibouchina cardinalis (Bonpl. Cogn.) Cogn. & 21764 & Arbusto & $\mathrm{T}$ & Q \\
\hline Tibouchina cerastifolia Cogn. & 26514 & Herbácea & $\mathrm{T}$ & $\mathrm{C}$ \\
\hline Tibouchina fasciculata Mart. & 24253 & Arbustiva & $\mathrm{T}$ & Q \\
\hline Tibouchina fothergillae (Schrank \& Mart. ex DC.) Cogn. & 21763 & Arbórea & $\mathrm{T}$ & C / Q - TM \\
\hline Tibouchina frigidula (DC.) Cogn. & 23964 & Arbustiva & $\mathrm{T}$ & Q \\
\hline Tibouchina gracilis (Bonpl.) Cogn. & 94870 & Arbustiva & $\mathrm{T}$ & Q \\
\hline Tibouchina herbacea (DC.) Cogn. & 24203 & Arbustiva & $\mathrm{T}$ & Q \\
\hline Tibouchina heteromalla (D.Don) Cogn. & 21765 & Arbustiva & $\mathrm{T}$ & $\mathrm{C}$ \\
\hline Tibouchina hieracioides (DC.) Cogn. & 25029 & Arbustiva & $\mathrm{T}$ & $\mathrm{C}$ \\
\hline Tibouchina martiusiana (DC.) Cogn. & 24060 & Arbustiva & $\mathrm{T}$ & Q \\
\hline Trembleya laniflora (D.Don) Cogn. & 21783 & Arvoreta & $\mathrm{T}$ & Q \\
\hline Trembleya parviflora (D.Don) Cogn. & 32041 & Arvoreta & $\mathrm{T}$ & Q \\
\hline \multicolumn{5}{|l|}{ MENISPERMACEAE } \\
\hline Cissampelos ovalifolia DC. & 25119 & Arbustiva & $\mathrm{T}$ & $\mathrm{C}$ \\
\hline Odontocarya tamoides (DC.) Miers & 28538 & Lian. Herb. & $\mathrm{T}$ & $Q-T M$ \\
\hline \multicolumn{5}{|l|}{ MYRTACEAE } \\
\hline Blepharocalyx salicifolius (Kunth) O. Berg & 26144 & Arbustiva & $\mathrm{T}$ & $\mathrm{C}$ \\
\hline Campomanesia adamantium (Cambess.) O.Berg. & 25301 & Arbustiva & $\mathrm{T}$ & Q \\
\hline Campomanesia pubescens (DC.) O.Berg. & 22344 & Arbustiva & $\mathrm{T}$ & $\mathrm{C}$ \\
\hline Campomanesia rufa (O.Berg.) Nied. & 26154 & Arbustiva & $\mathrm{T}$ & $C / Q$ \\
\hline Eugenia bimarginata DC. & 26026 & Arbustiva & $\mathrm{T}$ & Q \\
\hline Eugenia punicifolia (Kunth) DC. & 25251 & Arbustiva & $\mathrm{T}$ & $C / Q$ \\
\hline Eugenia modesta DC. & 25100 & Arbustiva & $\mathrm{T}$ & C \\
\hline Eugenia sonderiana O.Berg & 90572 & Arvoreta & $\mathrm{T}$ & $\mathrm{C}-\mathrm{TM}$ \\
\hline Gomidesia eriocalyx (DC.) O.Berg & 25124 & Arbustiva & $\mathrm{T}$ & $\mathrm{C}-\mathrm{TM}$ \\
\hline Myrceugenia alpigena (DC.) Landrum & 25274 & Arbustiva & $\mathrm{T}$ & $C / Q$ \\
\hline Myrcia guianensis (Aubl.) DC. & 23954 & Arbustiva & $\mathrm{T}$ & $\mathrm{C}$ \\
\hline Myrcia laruotteana Cambess. & 25304 & Arbustiva & $\mathrm{T}$ & $\mathrm{C}$ \\
\hline Myrcia mutabilis (O.Berg) N.Silveira & 26289 & Arbustiva & $\mathrm{T}$ & $C / Q$ \\
\hline Myrcia retorta Cambess. & 90586 & Arbustiva & $\mathrm{T}$ & $\mathrm{C}$ \\
\hline
\end{tabular}


A flórula rupestre do Pico de Itabirito, Minas Gerais, Brasil

\begin{tabular}{|c|c|c|c|c|c|}
\hline Myrcia splendens (Sw.) DC. & 23949 & Arbustiva & $\mathrm{T}$ & $\mathrm{C}$ & \\
\hline Myrcia venulosa DC. & 90587 & Arbustiva & $\mathrm{T}$ & $\mathrm{C}$ & \\
\hline Pimenta pseudocaryophyllus (Gomes) Landrum & 90602 & Arbórea & $\mathrm{T}$ & $\mathrm{C}-\mathrm{TM}$ & \\
\hline Psidium firmum O.Berg & 25290 & Arbórea & $\mathrm{T}$ & Q & \\
\hline Psidium lagoense O.Berg & 26170 & Arbustiva & $\mathrm{T}$ & $\mathrm{C}$ & \\
\hline Psidium guineense $\mathrm{Sw}$. & 25083 & Arbustiva & $\mathrm{T}$ & Q & \\
\hline Siphoneugena densiflora O.Berg & 90603 & Arvoreta & $T$ & C / Q - TM & \\
\hline Siphoneugena crassifolia (DC.) Proença \& Sobral & 90583 & Arvoreta & $\mathrm{T}$ & C / Q - TM & \\
\hline \multicolumn{6}{|l|}{ NYCTAGINACEAE } \\
\hline Guapira noxia (Netto) Lundell & 25308 & Arvoreta & $\mathrm{T}$ & $\mathrm{C}$ & \\
\hline Guapira opposita (Vell.) Reitz & 25307 & Arvoreta & $\mathrm{T}$ & $\mathrm{C}$ & \\
\hline Guapira tomentosa (Casar.) Lundell & 26141 & Arbustiva & $\mathrm{T}$ & C & \\
\hline \multicolumn{6}{|l|}{ OCHNACEAE } \\
\hline Luxemburgia octandra A.St.-Hil. & 26278 & Arbustiva & $T$ & $C / Q$ & \\
\hline Ouratea floribunda (A.St.-Hil.) Engl. & 22345 & Arbustiva & $\mathrm{T}$ & $\mathrm{C}$ & \\
\hline Ouratea semiserrata (Mart. \& Nees) Engl. & 22176 & Arvoreta & $T$ & Q & \\
\hline Sauvagesia erecta L. & 90553 & Herbácea & $\mathrm{T}$ & Q & \\
\hline Sauvagesia racemosa A.St.-Hil. & 26371 & Herbácea & $\mathrm{T}$ & C & \\
\hline \multicolumn{6}{|l|}{ ONAGRACEAE } \\
\hline Ludwigia laruotteana (Cambess.) H.Hara & 25314 & Arbustiva & $T$ & $C / Q$ & \\
\hline Ludwigia nervosa (Poir.) H.Hara & 25315 & Herbácea & $\mathrm{T}$ & $C / Q$ & \\
\hline Ludwigia octovalvis (Jacq.) P.H.Raven & 25143 & Arbustiva & $\mathrm{T}$ & $C / Q$ & \\
\hline Ludwigia peruviana (L.) H.Hara & 24197 & Arbustiva & $\mathrm{T}$ & $\mathrm{C} / \mathrm{Q}$ & \\
\hline \multicolumn{6}{|l|}{ ORCHIDACEAE } \\
\hline $\begin{array}{l}\text { Acianthera prolifera (Herb. ex Lindl.) Pridgeon \& } \\
\text { M.W.Chase }\end{array}$ & 26076 & Herbácea & $\mathrm{S} / \mathrm{R}$ & $\mathrm{C}$ & \\
\hline Acianthera teres (Lindl.) Borba & 26077 & Herbácea & $S / R$ & $C / Q$ & \\
\hline Anathallis rubens (Lindl.) Pridgeon \& M.W.Chase & 26521 & Herbácea & $\mathrm{R} / \mathrm{E}$ & Q - TM & \\
\hline Bifrenaria aureofulva Lindl. & 23374 & Herbácea & $\mathrm{E}$ & C - TM & \\
\hline Bifrenaria tyrianthina var. magnicalcarata Hoehne & 26073 & Herbácea & $\mathrm{S} / \mathrm{R} / \mathrm{E}$ & $C / Q$ & \\
\hline Brasilidium crispum (Lodd.) Campacci & 26103 & Herbácea & $E$ & C - TM & EN \\
\hline Bulbophyllum glutinosum (Barb.Rodr.) Cogn. & 26129 & Herbácea & $E$ & C - TM & \\
\hline Bulbophyllum exaltatum Lindl. & 26106 & Herbácea & $\mathrm{E}$ & Q-M & \\
\hline Bulbophyllum weddellii (Lindl.) Rchb.f. & 26126 & Herbácea & $\mathrm{R} / \mathrm{E}$ & $C / Q$ & \\
\hline Christensonella subulat (Lindl.) Szlach.et al. & 26101 & Herbácea & $\mathrm{R} / \mathrm{E}$ & $C / Q$ & \\
\hline Cleistes paranaensis (Barb.Rodr.) Schltr. & 26127 & Herbácea & $\mathrm{T}$ & Q & \\
\hline Coppensia blanchetii (Rchb.f.) Campacci & 26104 & Herbácea & $S / R$ & $\mathrm{C}$ & \\
\hline Coppensia hydrophila (Barb.Rodr.) Campacci & 26105 & Herbácea & $S$ & Q & \\
\hline Coppensia warmingii (Rchb.f.) Campacci & 26518 & Herbácea & $S / R$ & C & VU \\
\hline Cyrtopodium parviflorum Lindl. & 26075 & Herbácea & $\mathrm{T}$ & Q & \\
\hline Elleanthus brasiliensis (Lindl.) Rchb.f. & 26102 & Herbácea & $\mathrm{R}$ & Q & \\
\hline Elleanthus crinipes Rchb.f. & 26391 & Herbácea & $\mathrm{R}$ & Q & \\
\hline Encyclia patens Hook. & 26097 & Herbácea & $\mathrm{E}$ & $\mathrm{Q}-\mathrm{TM}$ & \\
\hline Epidendrum campestre Lindl. & 21953 & Herbácea & $\mathrm{R}$ & Q & \\
\hline Epidendrum chlorinum Barb.Rodr. & 26069 & Herbácea & $E$ & Q-TM & \\
\hline
\end{tabular}




\begin{tabular}{|c|c|c|c|c|c|}
\hline Epidendrum dendrobioides Thunb. & 23270 & Herbácea & $\mathrm{S}$ & Q & \\
\hline Epidendrum denticulatum Barb. Rodr. & 26070 & Herbácea & $\mathrm{S} / \mathrm{R} / \mathrm{T}$ & $\mathrm{C}$ & \\
\hline Epidendrum martianum Lindl. & 26068 & Herbácea & $S / R$ & $\mathrm{C}$ & \\
\hline Epidendrum saxatile Lindl. & 26096 & Herbácea & $\mathrm{R} / \mathrm{E}$ & Q & \\
\hline Epidendrum secundum Jacq. & 26071 & Herbácea & $\mathrm{S} / \mathrm{R} / \mathrm{T}$ & $\mathrm{C}$ & \\
\hline Epistephium lucidum Cogn. & 26343 & Herbácea & $\mathrm{T}$ & Q & \\
\hline Epistephium sclerophyllum Lindl. & 26074 & Herbácea & $T$ & $Q$ & \\
\hline Galeandra montana Barb.Rodr. & 26078 & Herbácea & $\mathrm{R}$ & $C / Q$ & \\
\hline Habenaria brevidens Lindl. & 26092 & Herbácea & $\mathrm{T}$ & $Q$ & \\
\hline Habenaria caldensis Kraenzl. & 26081 & Herbácea & $\mathrm{T}$ & Q & \\
\hline Habenaria edwallii Cogn. & 26086 & Herbácea & A & $\mathrm{C}$ & \\
\hline Habenaria fluminensis Hoehne & 26085 & Herbácea & $\mathrm{T}$ & $\mathrm{C}$ & \\
\hline Habenaria imbricata Lindl. & 26088 & Herbácea & $\mathrm{T}$ & Q & \\
\hline Habenaria humilis Cogn. & 26090 & Herbácea & $T$ & $Q$ & \\
\hline Habenaria jaguariahyvae Kraenzl. & 26181 & Herbácea & $\mathrm{T}$ & $\mathrm{C}$ & \\
\hline Habenaria johannensis Barb.Rodr. & 90639 & Herbácea & $T$ & $\mathrm{C}$ & \\
\hline Habenaria nuda Lindl. & 26087 & Herbácea & $T$ & $\mathrm{C}$ & \\
\hline Habenaria obtusa Lindl. & 26083 & Herbácea & $\mathrm{T}$ & Q & \\
\hline Habenaria parviflora Lindl. & 26091 & Herbácea & $\mathrm{T}$ & Q & \\
\hline Habenaria petalodes Lindl. & 26093 & Herbácea & $\mathrm{T}$ & Q & \\
\hline Habenaria secundiflora Barb.Rodr. & 26089 & Herbácea & $T$ & $Q$ & \\
\hline Habenaria subviridis Hoehne \& Schltr. & 23373 & Herbácea & $\mathrm{T}$ & Q & \\
\hline Hadrolaelia pumila (Hook.) Chiron \& V.P.Castro & 26351 & Herbácea & $E$ & C - TM & \\
\hline Hoffmannseggella caulescens (Lindl.) H.G.Jones & 21962 & Herbácea & $\mathrm{S} / \mathrm{R}$ & $\mathrm{C}$ & EN \\
\hline Hoffmannseggella crispata (Thunb.) H.G.Jones & 21952 & Herbácea & $\mathrm{S} / \mathrm{R}$ & $\mathrm{C} / \mathrm{Q}$ & EN \\
\hline Hoffmannseggella liliputana (Pabst) H.G.Jones & 26095 & Herbácea & $\mathrm{R}$ & $\mathrm{C}$ & \\
\hline Isabelia violacea (Lindl.) Van den Berg \& M.W.Chase & 26098 & Herbácea & $\mathrm{R} / \mathrm{E}$ & Q - TM & \\
\hline Liparis vexillifera (Llave \& Lex.) Cogn. & 26109 & Herbácea & $\mathrm{T}$ & Q & \\
\hline Maxillaria ochroleuca Lodd. ex Lindl. & 26345 & Herbácea & $\mathrm{R} / \mathrm{E}$ & $\mathrm{Q}-\mathrm{TM}$ & \\
\hline Mesadenus glaziovii (Cogn.) Schltr. & 26115 & Herbácea & $S / T$ & $\mathrm{C}$ & \\
\hline Nitidocidium gracile (Lindl.) F.Barros \& V.T.Rodrigues & 23269 & Herbácea & $S / R$ & $\mathrm{C}$ & CR \\
\hline Ornithidium rigidum (Barb.Rodr.) M.A.Blanco \& Ojeda & 26100 & Herbácea & $\mathrm{R}$ & Q & \\
\hline Pelexia laminata Schltr. & 26113 & Herbácea & $T$ & Q & \\
\hline Polystachya estrellensis Rchb.f. & 26189 & Herbácea & $\mathrm{E}$ & C - TM & \\
\hline Prosthechea vespa (Vell.) W.E.Higgins & 26107 & Herbácea & $\mathrm{R} / \mathrm{E}$ & $C / Q$ & \\
\hline Rhetinantha notylioglossa (Rchb.f.) M.A.Blanco & 26099 & Herbácea & $\mathrm{R} / \mathrm{E}$ & & \\
\hline Sacoila lanceolata (Aubl.) Garay & 22487 & Herbácea & $\mathrm{T}$ & Q & \\
\hline Sarcoglottis homalogastra (Rchb.f. \& Warm.) Schltr. & 26111 & Herbácea & $T$ & $\mathrm{C}$ & CR \\
\hline Veyretia rupicola (Garay) F.Barros & 29571 & Herbácea & $\mathrm{S} / \mathrm{T}$ & $\mathrm{C}$ & \\
\hline Veyretia simplex (Griseb.) Szlach. & 23271 & Herbácea & $\mathrm{T}$ & Q & \\
\hline Zygopetalum maculatum (Kunth) Garay & 26108 & Herbácea & S & $\mathrm{C}$ & \\
\hline Zygopetalum sellowii Rchb.f. & 23348 & Herbácea & $\mathrm{S}$ & Q & \\
\hline \multicolumn{6}{|l|}{ OROBANCHACEAE } \\
\hline Buchnera juncea Cham. \& Schltdl. & 25077 & Arbustiva & $T$ & C & \\
\hline Buchnera lavandulacea Cham. \& Schltdl. & 24105 & Arbustiva & $T$ & Q & \\
\hline
\end{tabular}


A flórula rupestre do Pico de Itabirito, Minas Gerais, Brasil

\begin{tabular}{|c|c|c|c|c|c|}
\hline Esterhazya splendida J.C.Mikan & 25125 & Arbustiva & $\mathrm{T}$ & $\mathrm{C}$ & \\
\hline Physocalyx major Mart. & 23997 & Arbustiva & $\mathrm{T}$ & C & VU \\
\hline \multicolumn{6}{|l|}{ PASSIFLORACEAE } \\
\hline Passiflora amethystina J.C.Mikan & 26294 & Lian. Herb. & $\mathrm{T}$ & $\mathrm{C}-\mathrm{TM}$ & \\
\hline Passiflora haematostigma Mart. ex Mast. & 25146 & Lian. Herb. & $\mathrm{T}$ & $\mathrm{C}$ & \\
\hline Passiflora villosa Vell. & 26271 & Lian. Herb. & $\mathrm{T}$ & $\mathrm{C}$ & \\
\hline \multicolumn{6}{|l|}{ PENTAPHYLACACEAE } \\
\hline Ternstroemia brasiliensis Cambess. & 26139 & Arbustiva & $\mathrm{T}$ & $\mathrm{C}$ & \\
\hline \multicolumn{6}{|l|}{ PERACEAE } \\
\hline Pera glabrata (Schott) Poepp. ex Baill. & 26530 & Arbórea & $\mathrm{T}$ & $Q-T M$ & \\
\hline \multicolumn{6}{|l|}{ PHYLLANTHACEAE } \\
\hline Phyllanthus klotzschianus Müll.Arg. & 25102 & Arbustiva & $\mathrm{T}$ & $C-A A$ & \\
\hline Phyllanthus leptophyllus Müll.Arg. & 23995 & Herbácea & $\mathrm{T}$ & $\mathrm{C}$ & \\
\hline \multicolumn{6}{|l|}{ PHYTOLACCACEAE } \\
\hline Microtea paniculata Moq. & 26142 & Herbácea & $T$ & $\mathrm{C} / \mathrm{Q}$ & \\
\hline Microtea tenuifolia Moq. & 24469 & Herbácea & $\mathrm{T}$ & $\mathrm{C}$ & \\
\hline Phytolacca thyrsiflora Fenzl. ex J.A.Schmidt & 90599 & Herbácea & $\mathrm{T}$ & $\mathrm{C}$ & \\
\hline \multicolumn{6}{|l|}{ PIPERACEAE } \\
\hline Peperomia decora Dahlst. & 25095 & Herbácea & $S$ & $\mathrm{C}$ & \\
\hline Peperomia galioides Kunth & 26190 & Herbácea & $\mathrm{S}$ & $\mathrm{C}$ & \\
\hline Peperomia glabrifolia Yunck. & 24260 & Herbácea & $S$ & Q & \\
\hline Peperomia subrubrispica C.DC. & 25053 & Herbácea & $S$ & $\mathrm{C}$ & \\
\hline Peperomia velloziana Miq. & 26254 & Herbácea & $\mathrm{S}$ & $Q$ & \\
\hline \multicolumn{6}{|l|}{ POACEAE } \\
\hline Andropogon bicornis $\mathrm{L}$. & 26252 & Herbácea & $\mathrm{T}$ & $Q-A A$ & \\
\hline Andropogon leucostachyus Kunth & 24264 & Herbácea & $\mathrm{T}$ & $\mathrm{C}-\mathrm{AA}$ & \\
\hline Andropogon macrothrix Trin. & 25068 & Herbácea & $\mathrm{T}$ & $\mathrm{C}$ & \\
\hline Andropogon virgatus Desv. & 24201 & Herbácea & $\mathrm{T}$ & $\mathrm{C}$ & \\
\hline Aristida capillacea Lam. & 28565 & Herbácea & $\mathrm{T}$ & Q & \\
\hline Arundinella hispida (Humb. \& Bonpl. Ex Willd.) Kuntze & 25073 & Herbácea & $\mathrm{T}$ & $\mathrm{C}$ & \\
\hline Axonopus siccus (Nees) Kuhlm. & 23337 & Herbácea & $\mathrm{T}$ & $\mathrm{C}$ & \\
\hline Calamagrostis viridiflavescens (Poir.) Steud. & 90632 & Herbácea & $\mathrm{T}$ & $\mathrm{C}$ & \\
\hline Chusquea pinifolia (Nees) Nees & 24196 & Herbácea & $\mathrm{T}$ & Q & \\
\hline Cortaderia selloana (Schult.) Asch. & 24074 & Herbácea & $\mathrm{T}$ & Q & \\
\hline Dichanthelium sciurotis (Trin.) Davidse & 90636 & Herbácea & $\mathrm{T}$ & Q & \\
\hline Echinolaena inflexa (Poir.) Chase & 24092 & Herbácea & $\mathrm{T}$ & Q & \\
\hline Eragrostis articulata (Schrank) Nees & 90635 & Herbácea & $\mathrm{T}$ & $\mathrm{C}$ & \\
\hline Eriochrysis cayannensis P.Beauv. & 26253 & Herbácea & $\mathrm{T}$ & $Q$ & \\
\hline Ichnanthus bambusiflorus (Trin.) Döll & 26275 & Herbácea & $\mathrm{T}$ & Q & \\
\hline Ichnanthus longiglumis Mez & 26274 & Herbácea & $\mathrm{T}$ & Q & \\
\hline Melinis minutiflora P.Beauv. & 90634 & Herbácea & $\mathrm{T}$ & $\mathrm{C}$ & \\
\hline Microchloa indica (L.f.) P.Beauv. & 90626 & Herbácea & $\mathrm{T}$ & $\mathrm{C}$ & \\
\hline Otachyrium versicolor (Döll) Henrard & 24053 & Herbácea & $T$ & Q & \\
\hline Panicum cyanescens Nees ex Trin. & 24055 & Herbácea & $\mathrm{T}$ & Q & \\
\hline Paspalum carinatum Humb. \& Bonpl. ex Flüggé & 23957 & Herbácea & $\mathrm{T}$ & $C-A$ & \\
\hline
\end{tabular}


W. A.Teixeira \& J. P. Lemos Filho

\begin{tabular}{|c|c|c|c|c|c|}
\hline Paspalum polyphyllum Nees & 24095 & Herbácea & $\mathrm{T}$ & Q & \\
\hline Pennisetum setosum (Sw.) Rich. & 90638 & Herbácea & $\mathrm{T}$ & $C-A$ & \\
\hline Schizachyrium condensatum (Kunth) Nees & 90637 & Herbácea & $\mathrm{T}$ & C & \\
\hline Schizachyrium tenerum Nees & 25071 & Herbácea & $\mathrm{T}$ & $Q$ & \\
\hline Setaria parviflora (Poir.) Kerguélen & 26374 & Herbácea & $\mathrm{T}$ & $\mathrm{C}$ & \\
\hline Sorghastrum nutans (L.) Nash & 24093 & Herbácea & $\mathrm{T}$ & Q & \\
\hline Sporobolus aeneus (Trin.) Kunth & 24094 & Herbácea & $\mathrm{T}$ & Q & \\
\hline Sporobolus metallicolus Longhi-Wagner \& Boechat & 24087 & Herbácea & $\mathrm{T}$ & $\mathrm{C}$ & VU \\
\hline Steinchisma decipiens (Nees ex Trin.) W.V.Br. & 90633 & Herbácea & $\mathrm{T}$ & Q & \\
\hline \multicolumn{6}{|l|}{ POLYGALACEAE } \\
\hline Asemeia violácea (Aubl.) J.F.B.Pastore \& J.R.Abbott & 90555 & Herbácea & $\mathrm{T}$ & Q & \\
\hline Caamembeca oxyphylla (DC.) J.F.B.Pastore & 23946 & Arbustiva & $\mathrm{T}$ & Q & \\
\hline Monnina stenophylla A.St.-Hil. \& Moq. & 26060 & Herbácea & $\mathrm{T}$ & Q & \\
\hline Polygala poaya Mart. & 26036 & Arbustiva & $\mathrm{T}$ & Q & \\
\hline Polygala longicaulis Kunth & 25269 & Herbácea & $\mathrm{T}$ & Q & \\
\hline Polygala minima Pohl ex A.W.benn. & 12072 & Herbácea & $\mathrm{T}$ & $\mathrm{C}-\mathrm{AA}$ & \\
\hline Polygala tenuis DC. & 25116 & Herbácea & $\mathrm{T}$ & $\mathrm{C}$ & \\
\hline Polygala urbani Chodat & 26259 & Herbácea & $\mathrm{T}$ & $Q$ & \\
\hline \multicolumn{6}{|l|}{ POLYGONACEAE } \\
\hline Coccoloba scandens Casar. & 26306 & Lian. Lenh. & $\mathrm{T}$ & $\mathrm{C} / \mathrm{Q}-\mathrm{TM}$ & \\
\hline Polygonum punctatum Elliott & 94838 & Herbácea & $\mathrm{T}$ & $\mathrm{C}$ & \\
\hline \multicolumn{6}{|l|}{ PRIMULACEAE } \\
\hline Lysimachia arvensis (L.) U. Manns \& Anderb. & 29532 & Herbácea & $\mathrm{T}$ & Q & \\
\hline Myrsine emarginella Miq. & 25275 & Arbustiva & $\mathrm{T}$ & $\mathrm{C}$ & \\
\hline Myrsine guianensis (Aubl.) Kuntze & 25277 & Arbustiva & $\mathrm{T}$ & $Q$ & \\
\hline Myrsine umbellata Mart. & 22175 & Arbustiva & $\mathrm{T}$ & Q & \\
\hline \multicolumn{6}{|l|}{ PROTEACEAE } \\
\hline Roupala montana Aubl. & 25309 & Arbustiva & $\mathrm{T}$ & Q & \\
\hline \multicolumn{6}{|l|}{ ROSACEAE } \\
\hline Prunus myrtifolia (L.) Urb. & 22180 & Arbustiva & $\mathrm{T}$ & Q & \\
\hline Rubus brasiliensis Mart. & 23971 & Arbustiva & $\mathrm{T}$ & C & \\
\hline Rubus erythroclados Mart. ex Hook.f. & 29788 & Lian. Lenh. & $\mathrm{T}$ & Q & \\
\hline Rubus rosifolius $\mathrm{Sm}$. & 23925 & Arbustiva & $\mathrm{T}$ & $C / Q$ & \\
\hline \multicolumn{6}{|l|}{ RUBIACEAE } \\
\hline Alibertia rotunda (Cham.) K.Schum. & 25313 & Arbustiva & $\mathrm{T}$ & $\mathrm{C}$ & \\
\hline Amaioua intermedia Mart. ex Schult. \& Schult.f. & 25121 & Arbustiva & $\mathrm{T}$ & $\mathrm{C} / \mathrm{Q}-\mathrm{TM}$ & \\
\hline Augusta longifolia (Spreng.) Rehder & 25256 & Arbustiva & $\mathrm{T}$ & Q & \\
\hline Borreria capitata (Ruiz \& Pav.) DC. & 22049 & Herbácea & $\mathrm{T}$ & $\mathrm{C}-\mathrm{AA}$ & \\
\hline Borreria poaya (A.St.-Hil.) DC. & 25099 & Arbustiva & $\mathrm{T}$ & $\mathrm{C}$ & \\
\hline Borreria tenella (Kunth) Cham. \& Schltdl. & 25273 & Herbácea & $\mathrm{T}$ & Q & \\
\hline Borreria verticillata (L.) G.Mey. & 26283 & Herbácea & $\mathrm{T}$ & $\mathrm{C}$ & \\
\hline Coccocypselum erythrocephalum Cham. \& Schltdl. & 25118 & Herbácea & $\mathrm{T}$ & $\mathrm{C}-\mathrm{TM}$ & \\
\hline Declieuxia cordigera Mart. \& Zucc. ex Schult. \& Schult.f. & 25126 & Herbácea & $\mathrm{T}$ & Q & \\
\hline $\begin{array}{l}\text { Declieuxia oenanthoides Mart. \& Zuuc. ex Schult. \& } \\
\text { Schult.f. }\end{array}$ & 26138 & Herbácea & $\mathrm{T}$ & $\mathrm{C}$ & \\
\hline
\end{tabular}


A flórula rupestre do Pico de Itabirito, Minas Gerais, Brasil

\begin{tabular}{|c|c|c|c|c|c|}
\hline Diodella apiculata (Willd. ex Roem. \& Schult.) Delprete & 26367 & Herbácea & $\mathrm{S} / \mathrm{T}$ & $\mathrm{C}$ & \\
\hline Emmeorhiza umbellata (Spreng.) K.Schum. & 25103 & Lian. Herb. & $\mathrm{S} / \mathrm{T}$ & $\mathrm{C}-\mathrm{TM}$ & \\
\hline Galianthe angustifólia (Cham. \& Schltdl.) E.L.Cabral & 26303 & Herbácea & $\mathrm{T}$ & $\mathrm{C}$ & \\
\hline Galianthe cf. thalictroides (K.Schum.) E.L.Cabral & 25191 & Herbácea & $\mathrm{T}$ & $\mathrm{C}$ & \\
\hline Galianthe cf. valerianoides (Cham. \& Schltdl.) E.L.Cabral & 26304 & Herbácea & $\mathrm{T}$ & $\mathrm{C}$ & \\
\hline Galium noxium (A.St.-Hil.) Dempster & 26504 & Lian. Herb. & $\mathrm{S} / \mathrm{T}$ & $\mathrm{C}$ & \\
\hline Hillia parasitica Jacq. & 3153 & Lian. Herb. & $\mathrm{T}$ & $\mathrm{Q}-\mathrm{TM}$ & \\
\hline Hindsia longiflora (Cham.) Benth. & 25055 & Arbustiva & $\mathrm{T}$ & Q & \\
\hline Mitracarpus frigidus (Willd. ex Roem. \& Schult.) K.Schum. & 25087 & Herbácea & $T$ & $\mathrm{C}$ & \\
\hline Mitracarpus parvulus K.Schum. & 26372 & Herbácea & $\mathrm{T}$ & $\mathrm{C}$ & \\
\hline Palicourea rigida Kunth & 25133 & Arbustiva & $\mathrm{T}$ & Q & \\
\hline Psychotria stachyoides Benth. & 24003 & Herbácea & $\mathrm{T}$ & $\mathrm{C}$ & \\
\hline Psychotria vellosiana Benth. & 25190 & Arvoreta & $T$ & $\mathrm{C}$ & \\
\hline Psyllocarpus laricoides Mart. ex Mart. \& Zucc. & 25085 & Herbácea & $\mathrm{T}$ & Q & \\
\hline Remijia ferruginea (A.St.-Hil.) DC. & 25045 & Arbustiva & $T$ & Q & \\
\hline Rudgea sessilis (Vell.) Müll.Arg. subsp. Sessilis & 26280 & Arvoreta & $\mathrm{T}$ & $Q-T M$ & \\
\hline \multicolumn{6}{|l|}{ RUTACEAE } \\
\hline Dictyoloma vandellianum A.Juss. & 25044 & Arbórea & $\mathrm{T}$ & $\mathrm{C}-\mathrm{TM}$ & \\
\hline Zanthoxylum rhoifolium Lam. & 26305 & Arbórea & $\mathrm{T}$ & $\mathrm{C}-\mathrm{TM}$ & \\
\hline \multicolumn{6}{|l|}{ SALICACEAE } \\
\hline Casearia arborea (Rich.) Urb. & 26301 & Arbórea & $T$ & $\mathrm{C}$ & \\
\hline \multicolumn{6}{|l|}{ SANTALACEAE } \\
\hline Phoradendron interruptum (DC.) B.D.Jacks. & 29493 & Lenhosa & $\mathrm{H}$ & $\mathrm{C}$ & \\
\hline \multicolumn{6}{|l|}{ SAPINDACEAE } \\
\hline Cupania cf. vernalis Cambess. & 90563 & Arbórea & $\mathrm{T}$ & Q & \\
\hline Paullinia carpopoda Cambess. & 25081 & Arbustiva & $\mathrm{T}$ & $\mathrm{C}$ & \\
\hline Serjania erecta Radlk. & 23913 & Arbusto & $\mathrm{T}$ & $\mathrm{C}$ & \\
\hline Serjania paradoxa Radlk. & 25093 & Lian. Lenh. & $\mathrm{T}$ & $\mathrm{C}-\mathrm{TM}$ & \\
\hline Serjania reticulata Cambess. & 25145 & Lian. Lenh. & $T$ & C & \\
\hline \multicolumn{6}{|l|}{ SMILACACEAE } \\
\hline Smilax elastica Griseb. & 25110 & Lian. Herb. & $\mathrm{T}$ & C - TM & \\
\hline Smilax oblongifolia Pohl ex Griseb. & 22347 & Arbustiva & $T$ & $C / Q$ & \\
\hline \multicolumn{6}{|l|}{ SOLANACEAE } \\
\hline Athenaea picta (Mart.) Sendtn. & 94866 & Arbustiva & $\mathrm{T}$ & Q & \\
\hline Brunfelsia brasiliensis (Spreng.) L.B.Sm. \& Downs & 24049 & Arbustiva & $\mathrm{T}$ & $Q-T M$ & \\
\hline Calibrachoa elegans (Miers) Stehmann \& Semir & 25130 & Herbácea & $\mathrm{T}$ & $\mathrm{C}$ & $\mathrm{CR}$ \\
\hline Dyssochroma viridiflorum (Sims) Miers & 25012 & Arbustiva & $\mathrm{T}$ & Q & \\
\hline Solanum americanum Mill. & 25084 & Herbácea & $\mathrm{T}$ & Q & \\
\hline Solanum cladotrichum Dunal & 24058 & Arbustiva & $\mathrm{T}$ & $\mathrm{C}-\mathrm{TM}$ & \\
\hline Solanum didymum Dunal & 94864 & Arbustiva & $\mathrm{T}$ & $\mathrm{C}-\mathrm{TM}$ & \\
\hline Solanum granulosoleprosum Dunal & 25109 & Arbórea & $T$ & $\mathrm{C}-\mathrm{TM}$ & \\
\hline Solanum refractifolium Schtltd. & 25098 & Herbácea & $\mathrm{T}$ & $\mathrm{C}$ & \\
\hline Solanum sisymbrifolium Lam. & 94865 & Arbustiva & $\mathrm{T}$ & $\mathrm{C}$ & \\
\hline Solanum subumbellatum Vell. & 26191 & Arbustiva & $\mathrm{T}$ & $\mathrm{C}$ & \\
\hline Solanum stenandrum Sendtn. & 26265 & Herbácea & $\mathrm{T}$ & $C / Q$ & \\
\hline
\end{tabular}




\begin{tabular}{|c|c|c|c|c|c|}
\hline Solanum subumbellatum Vell. & 23351 & Arbustiva & $\mathrm{T}$ & $Q$ & \\
\hline \multicolumn{6}{|l|}{ STYRACACEAE } \\
\hline Styrax aureus Mart. & 22341 & Arbustiva & $\mathrm{T}$ & C - TM & VU \\
\hline \multicolumn{6}{|l|}{ SYMPLOCACEAE } \\
\hline Symplocos oblongifolia Casar. & 90564 & Arvoreta & $\mathrm{T}$ & C & \\
\hline Symplocos arbutifolia Casar. & 90581 & Arbustiva & $T$ & $C / Q$ & \\
\hline \multicolumn{6}{|l|}{ THYMELAEACEAE } \\
\hline Daphnopsis utilis Warm. & 26308 & Arbórea & $\mathrm{T}$ & Q & \\
\hline \multicolumn{6}{|l|}{ THEACEAE } \\
\hline Laplacea fructicosa (Schrad.) Kobuski & 25139 & Arbustiva & $T$ & $Q$ & \\
\hline \multicolumn{6}{|l|}{ TURNERACEAE } \\
\hline Turnera capitata Cambess. & 90579 & Herbácea & $\mathrm{T}$ & C - TM & \\
\hline Turnera oblongifolia Cambess. & 26360 & Herbácea & $T$ & C & \\
\hline \multicolumn{6}{|l|}{ VELLOZIACEAE } \\
\hline Barbacenia flava Mart. ex Schult. \& Schult.f & 23353 & Herbácea & $\mathrm{T}$ & Q & \\
\hline Barbacenia tomentosa Mart. & 24467 & Herbácea & $\mathrm{T}$ & C & \\
\hline Vellozia albiflora Pohl & 23350 & Herbácea & $T$ & $C / Q$ & \\
\hline Vellozia caruncularis Mart. ex Seub. & 23340 & Herbácea & $T$ & C & \\
\hline Vellozia compacta Mart. ex Schult. \& Schult.f. & 23291 & Herbácea & $T$ & $\mathrm{C} / \mathrm{Q}$ & \\
\hline Vellozia graminea Pohl. & 23292 & Herbácea & $T$ & $\mathrm{C}$ & \\
\hline Vellozia variabilis Mart. ex Schult. \& Schult.f. & 23376 & Herbácea & $T$ & $\mathrm{C}$ & \\
\hline Vellozia virgata Goethart \& Henrard & 23914 & Herbácea & $\bar{T}$ & C & \\
\hline \multicolumn{6}{|l|}{ VERBENACEAE } \\
\hline Lantana camara L. & 90530 & Arbustiva & $T$ & C & \\
\hline Lantana Iundiana Schauer & 22343 & Arbustiva & $T$ & $\mathrm{C}$ & \\
\hline Lippia corymbosa Cham. & 25092 & Arbustiva & $\bar{T}$ & $Q$ & EN \\
\hline Lippia florida Cham. & 25097 & Arbustiva & $T$ & $Q$ & $\mathrm{CR}$ \\
\hline Lippia hermannioides Cham. & 23375 & Arbustiva & $T$ & $Q$ & \\
\hline Lippia rotundifolia Cham. & 25089 & Arbustiva & $\bar{T}$ & Q & \\
\hline Lippia sericea Cham. & 25088 & Arbustiva & $\mathrm{T}$ & C & \\
\hline Lippia sidoides Cham. & 24052 & Arbustiva & $\mathrm{T}$ & C - TM & \\
\hline Stachytarpheta cayennensis (Rich.) Vahl & 26276 & Herbácea & $\mathrm{T}$ & $\mathrm{C}$ & \\
\hline Stachytarpheta glabra Cham. & 23991 & Arbustiva & $\bar{T}$ & $Q$ & \\
\hline \multicolumn{6}{|l|}{ VITACEAE } \\
\hline Cissus albida Cambess. & 23941 & Liana Lenh. & $T$ & C - TM & \\
\hline Cissus erosa Rich. & 24204 & Liana Herb. & $T$ & C & \\
\hline \multicolumn{6}{|l|}{ VOCHYSIACEAE } \\
\hline Qualea dichotoma (Mart.) Warm. & 26031 & Arbustiva & $T$ & $Q$ & \\
\hline Vochysia emarginata (Vahl) Poir. & 23951 & Arbustiva & $T$ & $C$ & \\
\hline Vochysia thyrsoidea Pohl & 24254 & Arbórea & $\mathrm{T}$ & Q & \\
\hline Vochysia tucanorum Mart. & 24067 & Arbórea & $T$ & $\mathrm{C} / \mathrm{Q}-\mathrm{TM}$ & \\
\hline \multicolumn{6}{|l|}{ XYRIDACEAE } \\
\hline Xyris asperula Mart. & 24464 & Herbácea & $T$ & Q & \\
\hline Xyris plantaginea Mart. & 23926 & Herbácea & $T$ & Q & \\
\hline
\end{tabular}


A flórula rupestre do Pico de Itabirito, Minas Gerais, Brasil

\section{Agradecimentos}

À Minerações Brasileiras Reunidas MBR e à VALE $S A$, pelo apoio logístico e financeiro e à CAPES, pela bolsa concedida. Aos especialistas que colaboraram na identificação das espécies, cuja lista completa seria demasiadamente grande.

\section{Referências}

ABREU, A.A. 1984. O planalto de Diamantina: um setor da Serra do Espinhaço em Minas Gerais. Orientação (Instituto de Geografia, USP) 5: 75-79.

AB'SABER, A.B. 1990. Paleoclimas quaternários e pré-história da América Tropical. II. Revta. Brasil. Biol. 50(4): 821-831.

ALMEIDA-ABREU, P.A. \& RENGER, F.E. 2002. Serra do Espinhaço Meridional: um orógeno de colisão do Mesoproterozóico. Revta. Bras. Geoc. 32(1): 114.

ALMEIDA-ABREU, P.A. 1993. A evolução geodinâmica da Serra do Espinhaço Meridional, Minas Gerais, Brasil. Tese de doutorado. Univ. Freiburg. Freiburg.

ALVES, R.J.V. \& KOLBEK, J. 2009. Summit vascular flora of Serra de São José, Minas Gerais, Brazil. Check List 5(1): 35-73.

ÂMBIO (Geologia e Engenharia Ambiental). Estudo e relatório de impacto ambiental EIA/RIMA, projeto Cata Branca da Minerações Brasileiras Reunidas S.A. ÂMBIO. Belo Horizonte.

APG (Angiosperm Phylogeny Group) III. An update of the Angiosperm Phylogeny Group classification for the orders and families of flowering plants: APG III. Bot. J. Linn. Soc. 161: 105-121.

BARRETO, H.L.M. 1949. Regiões fitogeográficas de Minas Gerais. Bol. Geogr. 14: 14-28.

BARRETO, H.L.M. 1935. Resultados de excursões na Serra do Cipó, no estado de Minas Gerais. Arch. Inst. Biol. Veg. 2: 7-11.

BENITES, V.M., SCHAEFER, C.E.G.R., SIMAS, F.N.B. \& SANTOS, H.G. 2007. Soils associated with rock outcrops in the Brazilian mountain ranges Mantiqueira and Espinhaço. Revista Brasil. Bot. 30(4): 569-577.

BOWERS, J.E., MCLAUGHLIN, S.P. 1982. Plant species diversity in Arizona. Madronõ 29: 227-233.

BRANDÃO, M., GAVILANES, M.L., LACA-BUENDIA, J.P., MACEDO, J.F. \& CUNHA, L.H.S. 1989. Flora da Serra de Itabirito, Minas Gerais - primeira contribuição. Daphne 3(2): 237-250.
BRANDÃO, M., GAVILANES, M.L., LACA-BUENDIA, J.P., MACEDO, J.F. \& CUNHA, L.H.S. 1991. Contribuição para o conhecimento da Cadeia do Espinhaço em Minas Gerais (Serra de Itabirito) III. Daphne 1(3): 39-41.

CERN (Consultoria e empreendimentos de recursos naturais Ltda). 2006. Estudo e relatório de impacto ambiental EIA/RIMA; projeto de expansão da Mina do Pico. CERN. Belo Horizonte.

CHRISTENHUSZ, M.J.M., ZHANG, X.-C. \& SCHNEIDER, H. 2011. A linear sequence of extant families and genera of lycophytes and ferns. Phytotaxa 19: 7-54.

CHRIST, H. 1900. Spicilegium Pteridologicum AustroBrasiliense. In W. Schwacke (ed.) Plantas novas mineiras, n.2. Imprensa Oficial. Cidade de Minas, p. 11-42.

COAN, A.I., SCATENA, V.L. \& GIULIETTI, A.M. 2002. Anatomia de algumas espécies aquáticas de Eriocaulaceae. Acta bot. bras. 16(4): 371-384.

CONCEIÇÃO, A.A. 2003. Ecologia da vegetação em afloramentos rochosos na Chapada Diamantina, Bahia, Brasil. Tese de doutorado. Universidade de São Paulo. São Paulo.

CONCEIÇÃO, A.A. 2000. Alerta para a conservação da biota na Chapada Diamantina. Ciência Hoje 27(159): 54-56.

CONCEIÇÃO, A.A. \& GIULIETTI, A.M. 2002. Composição florística e aspectos estruturais de campo rupestre em dois platôs do Morro do Pai Inácio, Chapada Diamantina, Bahia, Brasil. Hoehnea 29(1): 37-48.

CONCEIÇÃO, A.A. \& PIRANI, J.R. 2005. Delimitação de habitats em campos rupestres na Chapada Diamantina: substratos, composição florística e aspectos estruturais. Bol. Bot. Univ. São Paulo 23(1): 85-111.

CONCEIÇÃO, A.A. \& PIRANI, J.R. 2007. Diversidade em quatro áreas de campos rupestres na Chapada Diamantina, Bahia, Brasil: espécies distintas, mas riquezas similares. Rodriguésia 58(1): 193-206.

CONCEIÇÃO, A.A., RAPINI, A., PIRANI, J.R., GIULIETTI, A.M., HARLEY, R.M., SILVA, T.R., SANTOS, A.K., CORREIA, C., ANDRADE, I.M., COSTA, J.A.S., SOUZA, L.R.S., ANDRADE, M.J.G., FUNCH, R.R., FREITAS, T.A., FREITAS, A.M.M. \& OLIVEIRA, A.A. 2005. Campos rupestres. In F.A. Juncá, L. Funch \& W. Rocha (orgs.). Biodiversidade e conservação da Chapada Diamantina. Ministério do Meio Ambiente. Brasília, p. 153-180.

COSTA, C.M.R., HERMANN, G., MARTINS, C.S., LINS, L.V. \& LAMAS, I.R. 1998. Biodiversidade em Minas Gerais: um Atlas para sua conservação. Fundação Biodiversitas. Belo Horizonte. [mapa no site www.biodiversitas.org]. 
COUTINHO, L.M. 1978. O conceito de Cerrado. Revta. Brasil. Bot. 1(1): 17-23.

DERBY, O.A. 1906. The Serra do Espinhaço, Brazil. J. Geol. 14: 374-401.

DNPM 1958. Esboço geológico do Quadrilátero Ferrífero de Minas Gerais, Brasil. DNPM (Departamento Nacional de Produção Mineral).

DORR, J.V.N. 1969. Physiographic, stratigraphic and structural development of Quadrilátero Ferrífero Minas Gerais, Brazil. Geological survey professional paper, n. 641-A. United States Government. Washington,

EITEN, G. 1972. The Cerrado vegetation of Brazil. Bot. Gard. 38: 201-341.

ESCHWEGE, W.L.V. 1822. Geognostisches Gemälde von Brasilien und wahrscheinliches Muttergestein der Diamanten. Landes Industrie Comptoir. Weimar.

FERNANDES, P.E.C.A., MONTES, M.L., LOBÃO DE OLIVEIRA, F.L., GHIGNONE, J.I., SIGA Jr., O. \& FRANKE DE CASTRO, H.R. 1982. Geologia. In Projeto Radam Brasil. Folha SD. 23. Ministério das Minas e Energia. Rio de Janeiro, p. 25-204.

FERREIRA, M.B. \& MAGALHÃES, G.M. 1977. Contribuição para o conhecimento da vegetação da Serra do Espinhaço em Minas Gerais (Serras do Grão Mogol e da lbitipoca). In Anais do XXVI Congresso Nacional de Botânica. Academia Brasileira de Ciências. Rio de Janeiro, p. 189-202.

FUNDAÇÃO BIODIVERSITAS. 2012. Revisão das Listas das Espécies da Flora Ameaçadas de Extinção do Estado de Minas Gerais. Disponível em http://www.biodiversitas.org.br/listas-mg/ consulta.asp. Acesso em 22/07/2012.

GARDNER, G. 1846. Travels in the interior of Brazil. London.

GENTRY, A.H. 1986. Endemism in tropical versus temperate plant communities. In M.E. SOULÉ (ed.) Conservation biology, the science and diversity. Sinauer Associates. Sunderland, p. 153-181.

GIULIETTI, A.M., HARLEY, R.M., QUEIROZ, L.P., WANDERLEY, M.G.L. \& PIRANI, J.R. 2000. Caracterização e endemismos nos campos rupestres da Cadeia do Espinhaço. In Tópicos atuais em Botânica. VX Congresso Nacional de Botânica. Embrapa. Brasília, p. 311-318.

GIULIETTI, A.M., MENEZES, N.L., PIRANI, J.R., MEGURO, M. WANDERLEY, M.G.L. 1987. Flora da Serra do Cipó, Minas Gerais: caracterização e lista das espécies. Bol. Bot. Univ. São Paulo 9: 1151.
GIULIETTI, A.M., PIRANI, J.R. \& HARLEY, R.M. 1997. Espinhaco Range region: eastern Brazil. In S.D. Davis, V.H. Heywood, O. Herrera-Macbride, J. Villa-Lobos \& A.C. Hamilton (orgs.). Centres of plant diversity: a guide and strategy for their conservation. Vol. 3: The Americas. Information Press. Oxford, p. 397-404.

GIULIETTI, A.M. \& PIRANI, J.R. 1988. Patterns of geographic distribution of some plant species from the Espinhaço Range, Minas Gerais and Bahia, Brazil. In Vanzolini, P.E. \& Heyer, W.R. (eds.) Proceedings of a workshop on Neotropical distribution patterns. Academia Brasileira de Ciências. Rio de Janeiro, p. 39-69.

HADLEY, K.S. 1987. Vascular alpine plant distribution within the central and southern Rocky Mountains, U.S.A. Artic and Alpine Research 19(3): 242-251.

HARLEY, R. M. Evolution and distribution of Eriope (Labiatae), and its relatives, in Braszil. In: VANZOLINI, P. E. and HEYER, W. R. (Ed.) Proceedings of a workshop on Neotropical distribution pattern. Rio de Janeiro. Academia Brasileira de Ciências, 1988, p. 71-120.

HARLEY, R.M. 1995. Introduction. In B.L. Stannard (ed.). Flora of the Pico das Almas, Chapada Diamantina, Bahia, Brazil. Royal Botanic Gardens. Kew, p. 1-42.

HARPER, K.T., FREENAM, D.C., OSTLER, W.K. \& KLIKOFF, L.C. 1978. The flora of Great Basin mountain ranges: diversity, sources, and dispersal ecology. Great Basin Naturalist Mem. 2: 81-103.

HOEHNE, F.C. 1927. Aspectos e flora das serras de Minas Gerais: a flora das baixadas e das serras. Ceres 3: 85-93.

IBGE (Instituto Brasileiro de Geografia e Estatística). 1993. Mapa de vegetação do Brasil. IBGE. Rio de Janeiro.

JACOBI, C.M. \& CARMO, F.F. (orgs.) 2012. Diversidade florística nas cangas do Quadrilátero Ferrífero. Universidade Federal de Minas Gerais, Belo Horizonte.

JOLY, A.B. 1970. Conheça a vegetação brasileira. EDUSP e Polígono. São Paulo.

KAMINO, L.H.Y., OLIVEIRA-FILHO, A.T. \& STEHMANN, J.R. 2008. Relações florísticas entre as fitofisionomias florestais da Cadeia do Espinhaço, Brasil. Megadiversidade 4(1/2): 38-77.

KING, L.C. 1956. A geomorfologia do Brasil. Revta brasil. Geogr. 18: 147-265.

KÖPPEN, W. 1936. Das geographische System der Klimate. In W. Köppen \& R. Geiger (eds.) Handbuch der Klimatologie. Vol. 1. Gebr. Borntraeger. Berlin, p. 1-44. 
KRUCKEBERGER, A.R. \& RABINOWITZ, D. 1985. Biological aspects of endemism in higher plants. Ann. Rev. Ecol. Syst. 16: 447-479.

LIMA, L.R. \& PIRANI, 2003. O gênero Croton L. (Euphorbiaceae) na Cadeia do Espinhaço, Minas Gerais, Brasil. Bol. Bot. Univ. São Paulo 21(2): 299-344.

LISBOA, M. A. A flora de Ouro Preto. Revta. Escola Minas, v. 39, p. 1-10, 1971.

LOHMANN, L.G. \& PIRANI, J.R. 1996. Tecomeae (Bignoniaceae) da Cadeia do Espinhaço, Minas Gerais e Bahia, Brasil. Acta Bot. Bras. 10(1): 103-138.

MAGALHÃES, G.M. 1953. Contribuição ao estudo fitogeográfico das Velloziaceae de Minas Gerais. In Anais do IV Congresso Nacional de Botânica. Recife, p. 32-40.

MAGALHÃES, G. M. 1954. Contribuição para o conhecimento da flora dos campos alpinos de Minas Gerais. In Anais do V Congresso Nacional de Botânica. Porto Alegre, p. 227-304.

MAGALHÃES, G.M. 1956. Características de alguns tipos florísticos de Minas Gerais II. Revta. Brasil. Biol. 1: 76-92.

MAGALHÃES, G.M. 1966. Sobre os cerrados de Minas Gerais. An. Acad. Brasil. Ciênc. 38 (suppl.): 59-69.

MCLAUGHLIN, S.P. 1989. Natural floristic areas of the western United State. J. Biogeogr. 16(3): 239-248.

MCLAUGHLIN, S.P. 1986. Floristic analysis of the southwestern United States. Great Basin Naturalist 46(1): 46-65.

MENEZES, N.L. \& GIULIETTI, A.M. 1986. Campos rupestres: paraíso botânico na Serra do Cipó. Ciência Hoje 5(25): 38-44.

MITTERMEIER, R.A., MYERS, N., GIL, P.R. \& MITTERMEIER, G.G. 1999. Hotspots: earth's biologically richest and most endangered terrestrial ecoregions. CEMEX. México.

MOREIRA, A.N.N. 1977. Relevo. In IBGE (Ed.) Geografia do Brasil. Região Nordeste. IBGE. Rio de Janeiro, p. 1-45.

MORELATO, P.C. \& ROSA, N.A. 1991. Caracterização de alguns tipos de vegetação na região amazônica, Serra dos Carajás, Pará, Brasil. Revta Brasil. Bot. 14(1): 1-141.

OLIVEIRA-FILHO, A.T. \& FLUMINHAN-FILHO, 1999. Ecologia da vegetação do parque florestal Quedas do Rio Bonito. Cerne (Lavras) 5(2): 51-64.

PEREIRA, M.C. 1994. Estrutura das comunidades vegetais de afloramentos rochosos dos campos rupestres do Parque Nacional da Serra do Cipó, MG. Dissertação de mestrado. Universidade Federal de Minas Gerais. Belo Horizonte.
PIRANI, J.R., MELLO-SILVA, R. \& GIULIETTI, A.M. 2003. Flora de Grão-Mogol, Minas Gerais, Parte I, Pteridófitas, Podocarpaceae, Angiospermas A-D. Bol. Bot. Univ. São Paulo 21(1): 1-249.

POHL, J.E. 1837. Reise im Innern von Brasilien. Wien.

PRANCE, G.T. 1994a. A comparison of the efficacy of higher taxa and species number in the assessment of biodiversity in the tropics. Phill. Trans. R. Soc. Lond. B. 345: 89-99.

PRANCE, G.T. 1994b. The use of phytogeographic data for conservation planning. In P.I.Forey, C.J. Humphries \& R.I. Vane-Wright (eds.) Systematics and conservation evaluation. Clarendon Press. Oxford, p. 145-163.

PROBIO - Projeto de conservação e utilização sustentável da diversidade biológica brasileira. 2000. Avaliação e ações Prioritárias para Conservação da Biodiversidade da mata atlântica e campos sulinos. Escala 1: 3.000.000.

RENGER, F.E. 1979. Evolução dos conceitos geológicos da Serra do Espinhaço. Atas do $1^{\circ}$ Simpósio de Geologia de Minas Gerais. Diamantina, p. 9-27.

RIZZINI, C.T. 1979. Tratado de fitogeografia do Brasil: aspectos sociológicos e florísticos. HUCITEC/EDUSP. São Paulo.

RODELA, L.G. 1998. Cerrados de altitude e campos rupestres do Parque Estadual do Ibitipoca, sudeste de Minas Gerais. Revta.Depto Geogr. Univ. São Paulo 1: 163-189.

ROMERO, R. \& NAKAGIMA, J.N. 1999. Espécies endêmicas do Parque Nacional da Serra da Canastra, Minas Gerais. Revta. Bras. Bot. 22(2): .

ROSENZWEIG, M.L. 1995. Species diversity in space and time. Cambridge University Press. Cambridge.

SAINT-HILAIRE, A.F.C.P. 1833. Voyage dans le District des Diamants et sur le littoral du Brésil. Vol. 1. Librairie-Gide. Paris.

SAINT-HILAIRE, A.F.C.P. 1975. Viagem pelas províncias do Rio de Janeiro e Minas Gerais. Livraria Itatiaia Editora. Belo Horizonte.

SECCO, R.S. \& MESQUITA, A.I. 1983. Notas sobre a vegetação de canga na Serra Norte - I. Bol. Mus. Para. Emílio Goeldi, ser. Botânica, 59: 1-13.

SILVA, M.F.F. 1992. Distribuição de metais pesados na vegetação metalófita de Carajás. Acta bot. bras. 6(1): 107-122.

SILVA, M.F.F. 1991. Análise florística da vegetação que cresce sobre canga hematítica em Carajás, Pará (Brasil). Bol. Mus. Para. Emílio Goeldi, sér. Botânica, 7(1): 79-105.

SILVEIRA, A.A. 1908. Flora e serras mineiras. Imprensa Official. Belo Horizonte. 
SILVEIRA, A.A. 1928. Floralia montium: Eriocauláceas. Vol. 1. Imprensa Official. Belo Horizonte.

SILVEIRA, A.A. 1931. Floralia montium: notas botânicas, geológicas e geographicas. Vol. 2 . Imprensa Official. Belo Horizonte.

SIMPSON, G.G. \& TODZIA, C.A. 1990. Patterns and processes in the development of the High Andean flora. Amer. J. Bot. 77(11): 1419-1432.

SMITH, A.R., PRYER, K.M., SCHUETTPELZ, E. , KORALL, P., SCHNEIDER, H. \& WOLF, P.G. 2006. A classification for extant ferns. Taxon 55(3): 705-731.

SMITH, A.R., PRYER, K.M., SCHUETTPELZ, E. , KORALL, P., SCHNEIDER, H. \& WOLF, P.G. 2008. Fern classification. In T.A. Ranker \& C.H. Haufler (eds.) The biology and evolution of ferns and lycophytes. Cambridge Univ. Press, Cambridge, p. 419-469.

SOUZA, V.C., LORENZI, H. 2012. Botânica sistemática: guia ilustrado para identificação das famílias de Angiospermas da flora brasileira, baseado em APG III. Ed. 3. Instituto Plantarum, Nova Odessa.

SPIX, J.B. \& MARTIUS, C.F.P. 1828. Reise in Brasilien. Lindauer. München.

STEHMANN, J.R., MOURÃO, A. 2007. Levantamento da flora do campo rupestre sobre canga hematítica couraçada remanescente na Mina do Brucutu, Barão de Cocais, Minas Gerais, Brasil. Rodriguésia 58(4): 775-786.

TAYLOR, D.W. 1977. Floristic relationships along the Cascade-Sierran axis. Amer. Midland Naturalist 97(2): 333-349.

TEIXEIRA, W.A. 1997. Estudo de fatores ambientais atuantes na colonização vegetal espontânea de uma área minerada de ferro. Disseratção de mestrado. Instituto de Ciências Biológicas, Universidade Federal de Minas Gerais. Belo Horizonte.
TEIXEIRA, W.A., LEMOS-FILHO, J.P. 1998. Metais pesados em folhas de espécies lenhosas, colonizadoras de mina de ferro em Itabirito, Minas Gerais. Revta Árvore, Viçosa, 22(3): 381-387.

TEIXEIRA, W.A., LEMOS-FILHO, J. P. 2002. Fatores edáficos e a colonização de espécies lenhosas em uma cava de mineração de ferro em Itabirito, Minas Gerais. Revta. Árvore, Viçosa, 26(1): 25-33.

UHLEIN, A. 1991. Transição cráton - faixa dobrada: exemplo do Cráton do São Francisco e da Faixa Araçuaí (Ciclo Brasiliano) no Estado de Minas Gerais. Tese de doutorado. Instituto de Geociências, Universidade de São Paulo.

URURAHY, J.C.C., COLLARES, J.E.R., SANTOS, M.M., BARRETO, R.A.A. 1984. Vegetação - As regiões fitoecológicas, sua natureza e seus recursos econômicos - estudo fitogeográfico. Folha SF. 23/24 Rio de Janeiro/Vitória. Volume 32 da Série Levantamento de Recursos Naturais do Projeto RADAMBRASIL. Rio de Janeiro.

VALADÃO, R.C. 1998. Evolução de longo-termo do relevo do Brasil Oriental: desnudação, superfícies de aplanamento e soerguimentos crustais. Tese de doutorado. Instituto de Geociências, Universidade Federal da Bahia. Salvador.

VITTA, F.A. 1995. Composição forística e ecologia de comunidades campestres na Serra do Cipó, Minas Gerais. Dissertação de mestrado. Instituto de Biociências, Universidade de São Paulo. São Paulo.

ZAPPI, D.C., LUCAS, E., STANNARD, B.L., LUGHADHA, E.N., PIRANI, J.R., QUEIROZ, L.P., ATKINS, S., HIND, D.J.N., GIULIETTI, A.M., HARLEY, R.M., CARVALHO, A.M. 2003. Lista das plantas vasculares de Catolés, Chapada Diamantina, Bahia, Brasil. Bol. Bot. Univ. São Paulo 21(2): 251-400. 